\title{
Impact of Sustainable Electricity for Cameroonian Population through Energy Efficiency and Renewable Energies
}

\author{
Fotsing Metegam Isabelle Flora', Njomo Donatien'1, René Tchinda ${ }^{2}$, Oumarou Hamandjoda ${ }^{3}$ \\ ${ }^{1}$ Environmental Energy Technologies Laboratory (EETL) of the University of Yaounde 1, Yaounde, Cameroon \\ ${ }^{2}$ Laboratory of Industrial Systems and Environment of the University of Dschang, Dschang, Cameroon \\ ${ }^{3}$ Energetic Laboratory, National Higher Polytechnic School, Yaounde, Cameroon \\ Email: fotsing85@yahoo.fr, dnjomo@usa.net, ttchinda@yahoo.fr, oumahama@yahoo.com
}

How to cite this paper: Flora, F.M.I. Donatien, N., Tchinda, R. and Hamandjoda, O. (2019) Impact of Sustainable Electricity for Cameroonian Population through Energy Efficiency and Renewable Energies. Journal of Power and Energy Engineering, 7, 11-51.

https://doi.org/10.4236/jpee.2019.79002

Received: August 15, 2019

Accepted: September 15, 2019

Published: September 18, 2019

Copyright $\odot 2019$ by author(s) and Scientific Research Publishing Inc. This work is licensed under the Creative Commons Attribution International License (CC BY 4.0).

http://creativecommons.org/licenses/by/4.0/

\begin{abstract}
Access to electricity and a reliable supply of energy are essential elements of local economic development and poverty reduction. To address these challenges, appropriate policies and mechanisms at the national and regional levels need to be implemented. In this study, we used Johanson cointegration and Granger causality techniques to examine the different cointegration and causal relationships that exist between the growth of electricity consumption (CE) and socio-economic parameters (GDP, tertiary GDP, GDP per capita, number of households, number of subscribers and population) in Cameroon during the period from 1975 to 2011. The results from the software Eviews 7.2 show that there are cointegration relationships between electricity consumption and socio-economic indicators (LGDPH, LPO and LS) thus reflecting the long-term relationship between socio-economic growth and electricity consumption (CE). Consumption growth could, therefore, follow socio-economic growth. In addition, the analysis of the Granger causality test results reveals that there is a unidirectional causal relationship of macroeconomic indicators towards electricity consumption. That is, LGDPG to LCE, LGDPH to LCE, and LGDPT to LCE. There is also a unidirectional relationship between LCE and the demographic indicators that is the relationship of LCE to LS (number of subscribers). We can, therefore, conclude that the indicators that have a better influence on electricity consumption are the overall GDP for the macroeconomic indicators and the population for the socio-demographic indicators respectively. In addition, the analysis of renewable energy potential (EnRs) shows us that Cameroon enjoys good irradiation throughout its territory, hence its high solar potential. The wind speed is unevenly distributed over the territory, it has an average speed in the region of
\end{abstract}


the very north of the country, but a low speed in the rest of the territory, which justifies the low wind potential in the country. We also noticed that the forest is concentrated in the southernmost part of the country, mainly in the eastern and southern regions. After study, we concluded that it is possible to truncate thermal power plants with renewable energy plants. We proposed to trade the thermal power stations of additions by biomass plants. We also offer hybrid solar-biomass power plants for isolated power plants; and solar-wind hybrid power plants for the Far North region of the country, given its strong wind power potential. We also identified the sources of over-consumption and estimated the amount of energy that could be saved by developing an energy efficiency plan (10\%) with the standard scenario that would take into account good energy-saving practices. We then estimated at $336,938 \mathrm{Kg}$ the gain in $\mathrm{CO}_{2}$ emissions if we exchanged the thermal power stations into EnRs. Recommendations are then suggested for the successful implementation of an energy efficiency plan and implementation of renewable energy in Cameroon.

\section{Keywords}

Energy Efficiency, Renewable Energy, Cointegration, Causality, Fossil Fuels, Mini-Grids

\section{Introduction}

In recent decades, global warming has increased dramatically, as evidenced by the continuing deterioration of the environment due to economic growth based on traditional energy consumption. Energy is the building block of the development of economic activity and has increased its demand as a result of the overall modernization of the economy. One of the pillars of the fight against climate change is to reduce greenhouse gas (GHG) emissions through the use of sustainable energies, such as biofuels, biomass, hydroelectricity, solar energy, the wind.

The strong economic growth of Cameroon for more than ten years is accompanied by an increase in the demand for electricity consumption. In 2012, electricity consumption accounted for only 7.3\% of Cameroon's energy consumption. One of the main reasons for this low ratio is the country's low electrification rate. It has increased over the $2005-2011$ period, from $49.7 \%$ to $57 \%$, thanks to the government's efforts to expand and intensity the electricity grid. This effort has had very positive effects in urban areas but poor results in rural areas where the majority of the population remains without access to the electricity grid: the rate of rural electrification stagnates around $19 \%$.

The current energy situation in Cameroon characterized by power cuts, aging electrical installations has negative impacts on the daily lives of Cameroonians. Unstable access to electricity has direct impacts. It makes difficult the functioning of government and the state basic services. In rural areas without access to electricity, health centers can only provide very limited care and cannot refrige- 
rate vaccines and fragile medicines. Without light, children cannot easily study at night. More and more families are leaving their farms which are their livelihood to join the ranks of the poorest people on the outskirts of urban areas. The energy crisis in Cameroon also has economic impacts: electricity is very expensive and is only accessible to the most affluent classes. Unstable access to the network hampers the development of businesses and economic activities. It also results in significant food wastage, because the food cannot be refrigerated. However, despite a huge potential in electricity and renewable energy, Cameroon has significant energy deficits. The country's resources are under-exploited and wasted during transport. As a result, the supply available to the population is largely insufficient.

The electrical operator ENEO, in charge of the management of the electricity system as a whole (production, transmission and distribution of electricity) is having difficulties to meet this strong demand, particularly at peak hours, and is not in a position of meeting all the electricity needs of the country, both in terms of quantity and quality of electricity delivered. Plans have been made to strengthen production capacity in the future, but it is certain that the necessarily long time frames for implementing these investment programs will not allow for quick and effective solutions to the current imbalance between supply and demand of electricity.

Energy efficiency and renewable energies thus become the essential instrument for responding in the short and medium term the growing consumer demand, but also as a long-term policy to reduce energy consumption and limit investment in electrical energy production. Energy efficiency means rational use of energy by increasing the efficiency of its production, transportation, distribution and final consumption. This is to disconnect economic growth (which must not be compromised at all) from energy growth. A one-way causality relationship of GDP to the electricity consumption of the population should be observed, so that it can be argued that the implementation of an energy efficiency policy will not jeopardize the country's economic growth. Thus the energy security of the country could be increased and substantial savings could be made in the import of fossil fuels whose price continues to grow. It should be noted that the cost of generating electricity from thermal power plants is more expensive than that generated by hydroelectric power plants. Since some thermal power plants are used for peak power management, controlling electricity demand would reduce the high demand at the peak and thus reduce the use of fossil fuels. It should also be noted that the consumption of fossil fuels produces greenhouse gases (GHGs) that are responsible for climate change. Cameroon, however, has huge resources in renewable energy that are biomass, hydropower, solar energy. These renewable energies are now the best way to fight against the observed climate change.

The acceleration of the development of mini-grids can play an important role in the problem posed by the ever-increasing demand for electricity in the coun- 
try. Mini-grid technologies are mature enough which can be fully integrated into rural electrification plans. In addition, the use of mini-grids based on renewable energies can provide electricity at a lower cost than using fossil fuels (fossil-fired power plants). They also increase energy security and improve adaptability under changing climatic conditions. Rural population could thus contribute to the production of their electricity by collecting biomass. However, in Cameroon, neither 2030 Electricity Sector Development Plan (ESDP 2030), 2035 Strategic Document for Growth and Employment (ECSD 2035), really seem to integrate renewable energies into development action programs, despite the diversified potential available through agro-ecological factors.

In this work, we will first present the socio-economic indicators likely to influence the consumption of electricity in Cameroon; we will then show the relationship between these indicators and electricity consumption. Then, we will present the current production of electricity in Cameroon (hydroelectric plants and thermal power plants) to evaluate the energy produced by thermal power plants. We will then present the potential of biomass, solar and wind power in Cameroon to show that it is possible to substitute thermal power plants for solar or biomass plants. We will then lead to a prospective modeling of the electricity demand of the Cameroonian population. A scenario test including energy efficiency will be done and an assessment of the $\mathrm{CO}_{2}$ emission gain and recommendations for the success of an energy efficiency plan and implementation of the EnRs will close this study. We will then present ten recommendations for the success of sustainable electrification in Cameroon. This may be an example for many developing countries.

\section{Literature Review}

\subsection{Socio-Demographic Indicators}

At the end of 2012, the total population of Cameroon was estimated at about 21.7 million, corresponding to an average density of 44.8 inhabitants $/ \mathrm{km}^{2}$ and a population growth of $2.54 \%$ (World Bank, 2018) [1]).

The spatial coverage of Cameroon's current electricity grid is subdivided into three networks, as follows:

- The South Interconnected Network (RIS) covering the six regions of the Center, Littoral, West, North-West, South-West and South.

- The North Interconnected Network (RIN) covering the three northern regions (Adamawa, North and Far North).

- And the East Network (RIE) which is not interconnected and whose spatial coverage is exclusively within the Eastern region.

The proportion of the population weight of the entire area covered by the RIS network (RIS area) is slowly decreasing (from $66.1 \%$ in 1976 to $61.9 \%$ in 2012 contrary to the RIN area, which has gradually recorded a little more socio-economic development in recent years (increased from $21.9 \%$ in 1976 to an estimated $34.2 \%$ in 2012). The weight of the eastern network area, heavily cov- 
ered by forest and sparsely populated, is decreasing (from $4.8 \%$ in 1976 to $4 \%$ in 2012) (INS, 2010) [2].

The proportion of the rural population in Cameroon continues to remain significant, i.e. $48 \%$ in 2010 according to the NSI's estimates, despite a clear downward trend since 1976. The rate of urbanization of the population in Cameroon is, however, from $28.5 \%$ in 1976 to $52 \%$ in 2010, reflecting sustained growth in the total urban population, with an average annual growth rate (AAGR) estimated at $4.6 \%$ over the entire period 1976-2010, compared with $1.5 \%$ average annual growth of the rural population. Poverty is more pronounced in rural areas, particularly in the three regions of the RIN zone, since the income of this population comes mainly from the agricultural sector and this sector is vulnerable to climatic hazards; the intermittency of the incomes it offers and its character which has remained traditional and very little mechanized in several regions of the country. Thus, poverty is most prevalent and accentuated among the employed labor force in the informal agricultural sector. Those with formal private or administrative activities appear to be the least affected by poverty. These activities are more developed in urban areas and in the largest socio-economic centers of the country, such as Douala and Yaounde.

Figure 1 shows the evolution of the distribution of the Cameroonian population until 2017. The analysis of Figure 1(a) shows us that in 2008, the percentage of the rural population falls below that of the urban population and reaches respectively $44 \%$ against $56 \%$. This decrease in the percentage of the rural population with respect to the urban population is mainly due to the rural exodus and the urbanization of several rural areas which thus become urban areas. The analysis in Figure 1(b) shows that the rate of access to electricity has changed significantly for the urban area, but has not changed much in the rural area.

\subsection{Macroeconomic Aggregates (INS, 2010) [2]}

The analysis of the real GDP structure for 2009 shows that the tertiary sector (trade, hotels and restaurants, transport and communication, finance and real estate, administrative services, miscellaneous services) was the main component of the national GDP, with an estimated share of nearly $47 \%$. Commercial activities, with restaurant and hotel services, are the mainstay of this sector, accounting for $20.1 \%$ of total national GDP, due to the low investment requirement compared to other economic sectors.

The share of the secondary sector (mining and extractions and oil activities included, manufacturing industries, construction, electricity, gas and water) represents the second largest economic sector, with a share estimated at nearly $30 \%$ of real GDP in 2009. Manufacturing industries represent here the main sub-sector, with a contribution to the national GDP of nearly $16 \%$, estimated in the same year.

The entire primary sector (agriculture, forestry and forestry extraction, fish- 
ing, hunting and livestock farming) accounted for less than a quarter of national GDP at constant prices, or nearly $23 \%$ in 2009 . The main primary subsector is subsistence agriculture, which accounted for $63 \%$ of primary GDP in the same year, compared to $13 \%$ for forestry, $12 \%$ for livestock and hunting, $6.5 \%$ for industrial and agricultural export and 5.5\% for fishing (INS, 2010) [2].

Figure 2 shows the electricity consumption in kWh per capita in Cameroon from 1971 to 2014 . We note that this consumption increases over time. The period from 2006 to 2011 corresponds to the period of strong growth of this electricity consumption by inhabitant. This can be justified by a greater electric coverage and the increase of electrical appliances in households as well as their standard of living.

\subsection{Context of Electric Power in Cameroon}

The electricity generation fleet managed by ENEO includes three hydroelectric plants, two of which supply the RIS, and nine thermal power plants connected to the grid, of which eight (8) are on the RIS. At the end of 2011, there were also 27 isolated generating stations, of which 12 exist in RIS-assisted areas, 8 in the

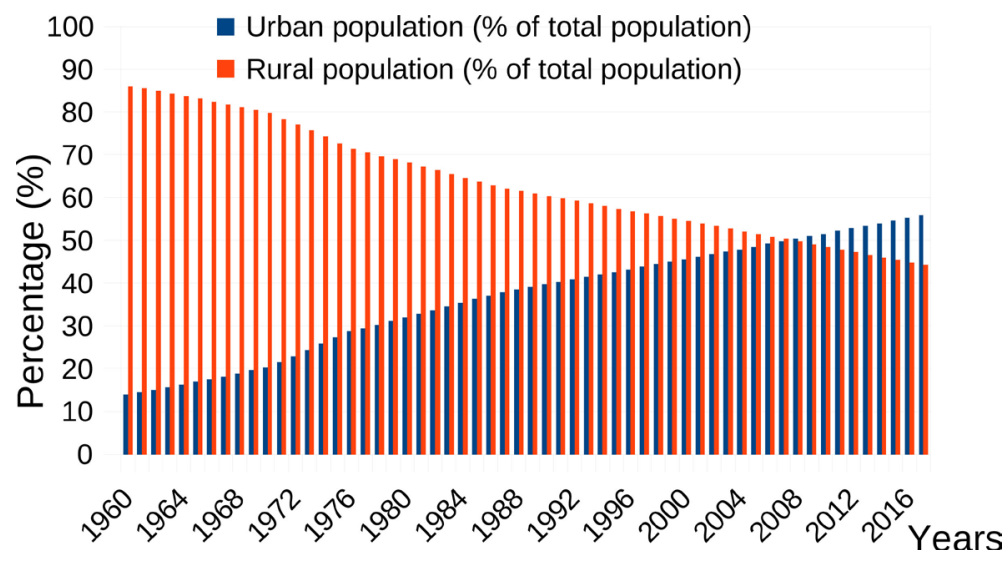

(a)

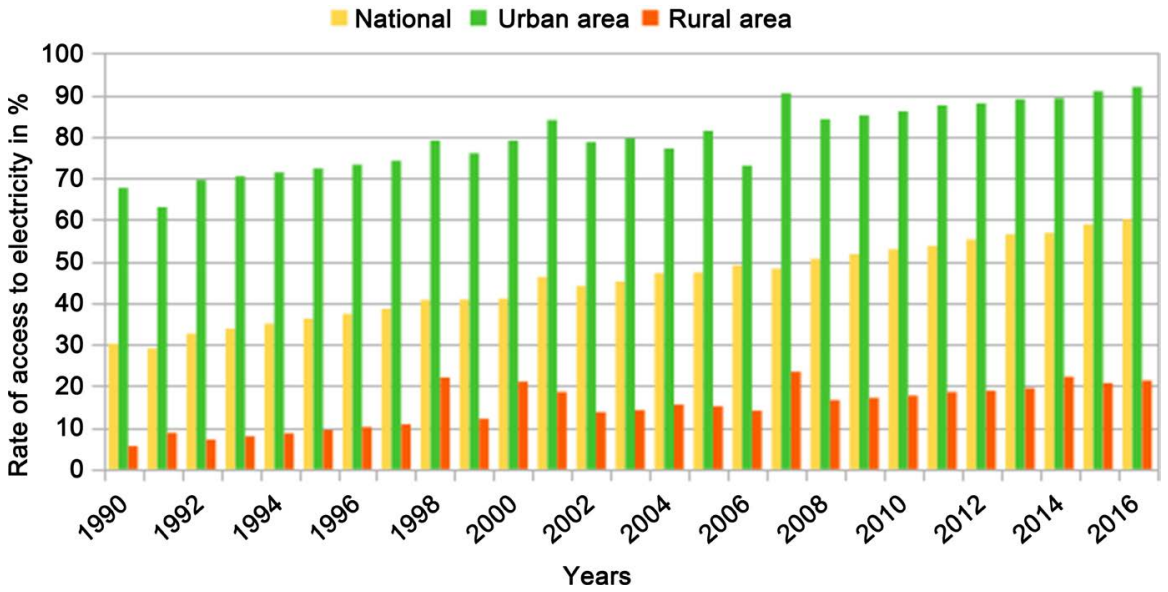

(b)

Figure 1. Evolution of the Cameroonian rural and urban population and rate of access to electricity (Source: World Bank, 2018) [1]. 


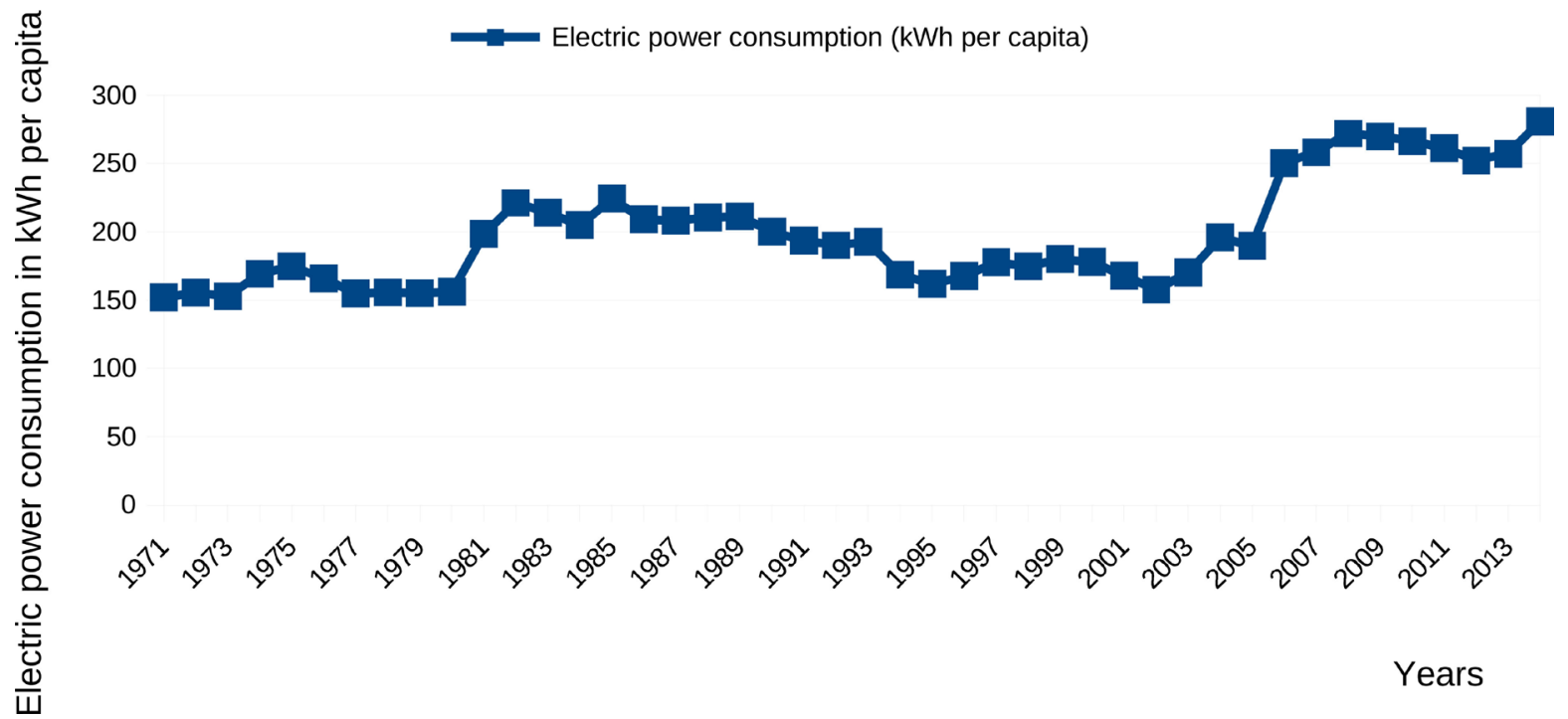

Figure 2. Evolution of the GDP per person employed in Cameroon (Source: World Bank, 2018) [1].

North regions served by the RIN, and 6 more are located in the Eastern network area. The latter will be designated by RIE, by analogy with RIS and RIN. Thus, more than $56 \%$ of the workforce of the electric park is concentrated in the large zone of the South with $83 \%$ of the main plants connected to the network and $44 \%$ of the isolated plants; this should reflect the relative importance of the demand for the Great South network. Hydroelectric generation accounted for the bulk of national production, with over $92 \%$ of the national production of power plants managed by ENEO over the period 2005-2011.

Isolated thermal power plants represented, for their part, an average of $1.6 \%$ of the national production of ENEO, with a maximum of $1.8 \%$ recorded in 2011. It should be recalled here that isolated thermal power plants supply very often isolated areas which correspond to rural areas. We understand why rural areas are not electrified. In Cameroon, most mini-grids rely solely on fossil fuels (fuel oil) for electricity generation. However, the use of renewable energies in mini-grids would reduce electricity generation costs, improve energy security and reduce environmental pollution.

Figure 3 shows the energy map of Cameroon. Blue hexes represent hydroelectric power stations, black power plants. We also represent the existing power grid in Cameroon. The various streams and roads are also represented in Figure 3 as well as population density. Figure 4 shows the proportions of energy sources produced in Cameroon. We find that hydropower production is predominant and is only rescued by oil-fired power plants up to 2006. However, starting in 2007, we see the introduction of a new source of energy production, which is natural gas from the Kribi gas station. Between 2006 and 2015, there was a drop in production of hydroelectric power plants in favor of a growing production of oil and gas thermal power plants.

Figure 5 shows the evolution of electricity production from different sources of energy in Cameroon, as well as the losses due to the transport and distribution 
of this electricity until 2015. The electricity production of the various power plants accounts for about $75 \%$ of the total production of all plants in 2015 . The share of oil-fired power plants is about $18 \%$ of the total and the gas-fired power plant about $6 \%$ in 2015. Let us recall here that electricity from gas-fired power

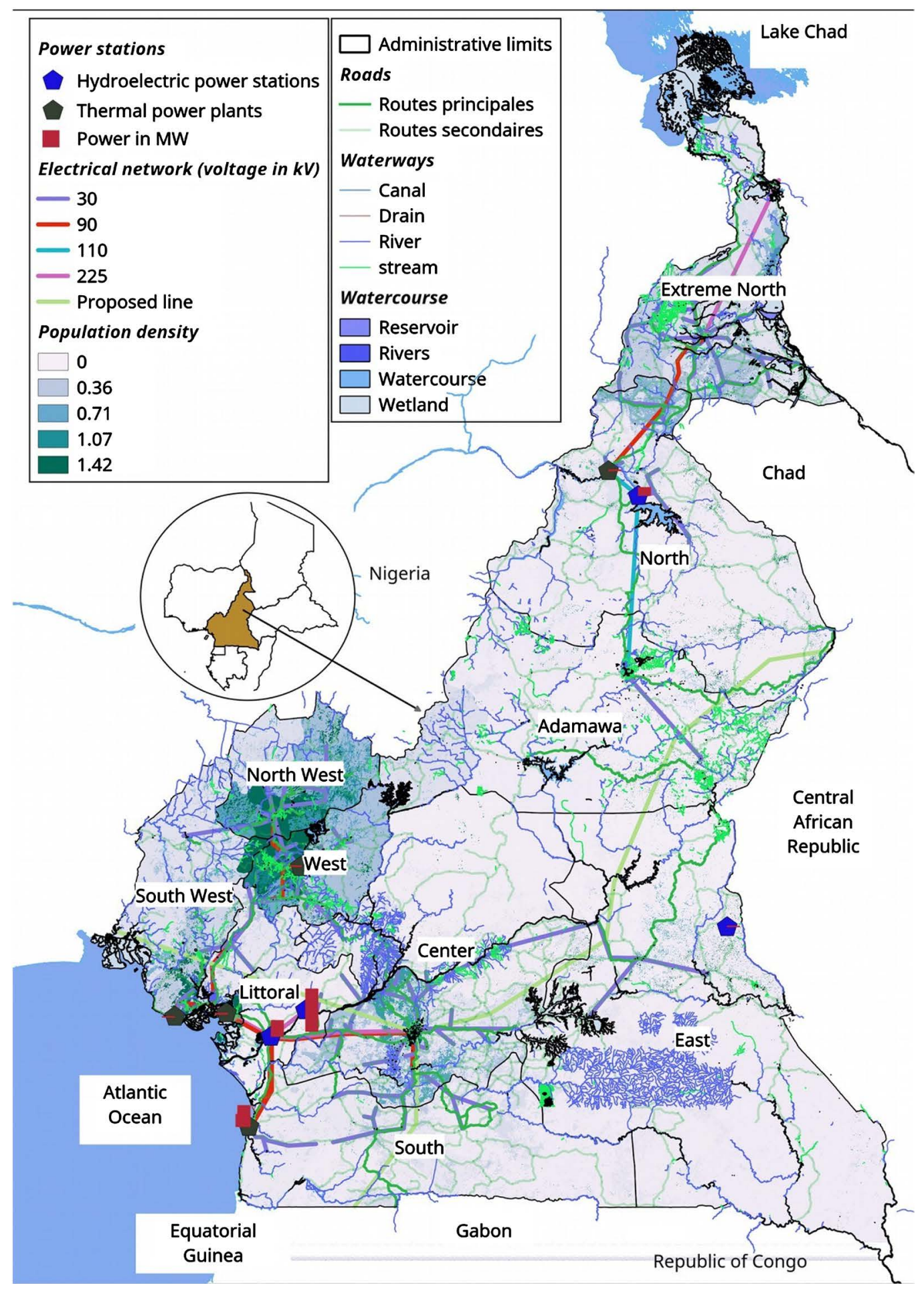

Figure 3. Energy map of Cameroon (Source: Worldpop 2010, OSM 2018, World Bank 2018, GADM 2018) [1] [3] [4] [5]. 
plants began in 2007 with the Kribi gas-fired power station. We can also note from Figure 5 that transmission and distribution losses accounted for more than $11 \%$ of total electricity generation in 2014 . This is due to the aging of transmission lines that are obsolete today. The new, more efficient transmission lines would improve the transport and distribution of electricity. Off-shored production would also reduce the length of transmission lines and thus the losses allocated to it.

Figure 6 shows the evolution per capita annual of electricity consumption and per capita as well as $\mathrm{CO}_{2}$ emissions in Cameroon. We can see that in 2014, annual per capita consumption was about $280 \mathrm{kWh}$, or about $0.76 \mathrm{kWh}$ per capita per day. This low per capita electricity consumption is due to the fact that a large part of the population is not yet electrified. This population is greatly constituted of the rural population which represents about $46 \%$ of the total population of Cameroon and therefore only about $22 \%$ had access to electricity in 2014 . We also find that the $\mathrm{CO}_{2}$ emission per capita is less than 0.7 metric tons. This $\mathrm{CO}_{2}$ emission per inhabitant decreases sharply over time and reaches 0.3 metric tons

- Hydroelectric sources (\% of total) $\quad$ Oil sources (\% of total) $\quad$ Natural gas sources (\% of total)

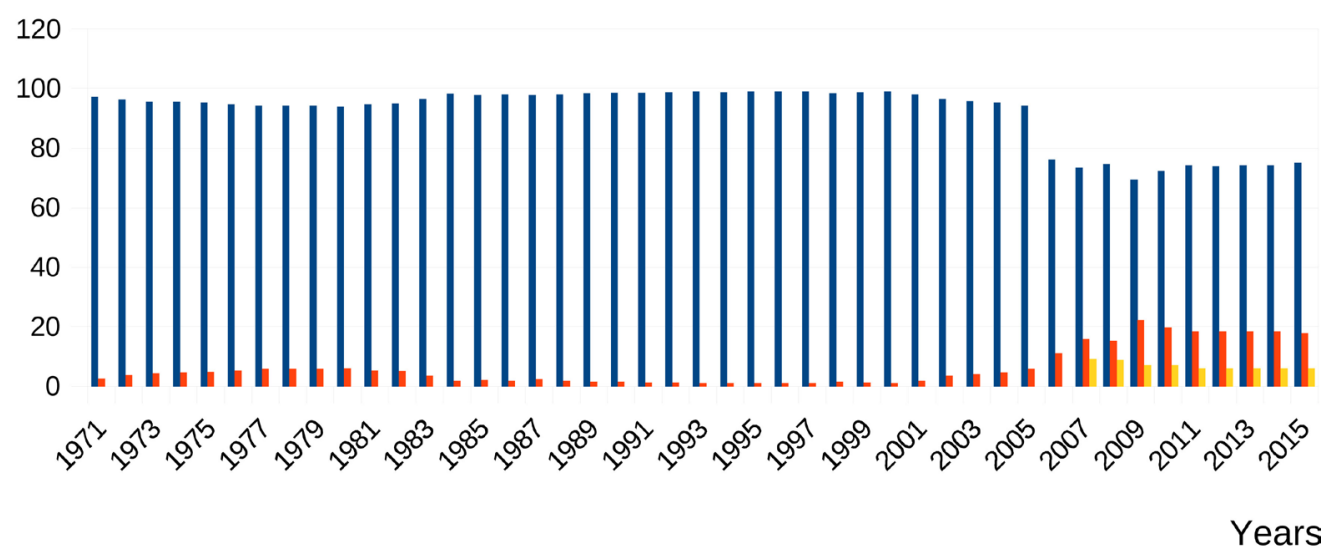

Figure 4. Proportion of sources of energy production in Cameroon (Source: World Bank 2018) [1].

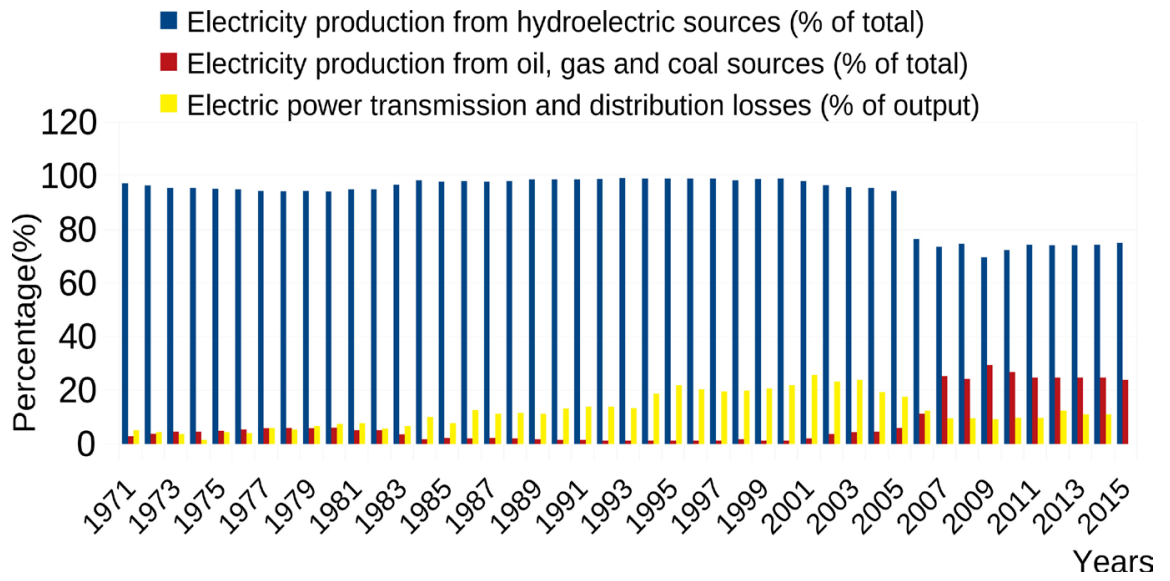

Figure 5. Electricity production of Cameroon and electric power transmission and distribution losses in percent of total (Source: World bank, 2018) [1]. 


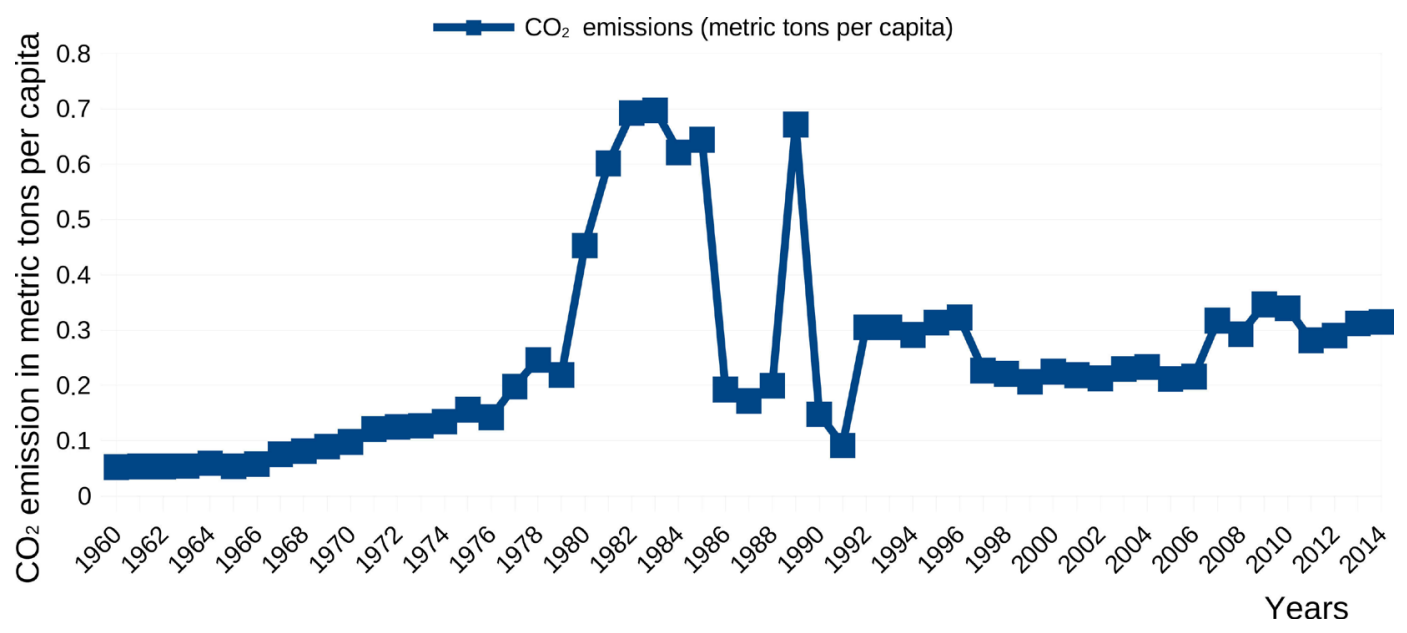

Figure 6. Electric power consumption and $\mathrm{CO}_{2}$ emission per capita of Cameroon (Source: World bank, 2018) [1].

in 2014. This low emission rate could be due to the fact that electricity production in 2014 was $74 \%$ hydroelectric and only $24 \%$ thermal (oil and natural gas). Remember that natural gas produces very little $\mathrm{CO}_{2}$ compared to fuel oil.

For the period of use of the plants during the peak, the calculations were made by comparing the energy produced at each plant to the annual peak of the same plant. The duration of use thus calculated for each plant makes it possible to convert the energy produced by a power plant (MWh) into peak power (in MW).

The study of the daily average load curves of RIS and RIN shows us that the daily peak is observed in both networks around $8 \mathrm{pm}$. This is due to the return of households in their different homes and the high use of electrical appliances and also lighting due to the darkness. We can also note that the peak of the RIS network always occurs, during the period studied, in December, on a working day around $8 \mathrm{pm}$. This peak has evolved with an average annual growth rate of 6.3\% per year between 2005 and 2011. Moreover, the tip of the RIN is shifted in time from two to three months compared to that of RIS. It took place, over the period considered, twice in February, but most often in March, on a working day around $8 \mathrm{pm}$. This peak has evolved at an average rate of $4.5 \%$ per year. For the period of use of the plants during the peak, the calculations were made by comparing the energy produced at each plant to the annual peak of the same plant. The duration of use thus calculated for each plant makes it possible to convert the energy produced by a power plant (MWh) into peak power (in MW).

\subsection{GHG Emissions in Thermal Power Plants}

Thermal power plants used in Cameroon use oil or gas.

We can see from Table 1 that electricity generation from hydro has the lowest $\mathrm{CO}_{2}$ emissions and that from coal has the highest emission. It should be noted that in Cameroon, thermal power plants mainly use heavy fuel oil (Yassa power plant), light fuel oil (other oil-fired power plants) and natural gas (Kribi power plant). Given the rising costs of these fossil fuels, geopolitical difficulties that 
Table 1. $\mathrm{CO}_{2}$ emission of the different electricity production sectors.

\begin{tabular}{ccccccccc}
\hline $\begin{array}{c}\text { Modes of } \\
\text { production }\end{array}$ & $\begin{array}{c}1 \mathrm{kWh} \\
\text { Hydraulic }\end{array}$ & $\begin{array}{c}1 \mathrm{kWh} \\
\text { Nuclear }\end{array}$ & $\begin{array}{c}1 \mathrm{kWh} \\
\text { Wind }\end{array}$ & $\begin{array}{c}1 \mathrm{kWh} \\
\text { Photovoltaic }\end{array}$ & $\begin{array}{c}1 \mathrm{kWh} \text { Thermal } \\
\text { combined cycle }\end{array}$ & $\begin{array}{c}1 \mathrm{kWh} \text { Thermal } \\
\text { Natural Gas }\end{array}$ & $\begin{array}{c}1 \mathrm{kWh} \\
\text { Thermal oil }\end{array}$ & $\begin{array}{c}1 \mathrm{kWh} \\
\text { Thermal Coal }\end{array}$ \\
\hline $\begin{array}{c}\mathrm{CO}_{2} \text { emission in } \mathrm{g} \\
\mathrm{CO}_{2} \text { eq/kWh }\end{array}$ & 4 & 6 & 3 à 22 & 60 à 150 & 427 & 883 & 891 & 978 \\
\hline
\end{tabular}

may arise from its supply (dependence on the Middle East), its future scarcity, its negative effects on the environment and disruption of climate change, it will be necessary to think of migrating towards renewable energies that are more respectful of the environment.

\subsection{Potentials of Renewable Energies in Cameroon}

Electricity consumption has increased in recent years with rapid growth in the residential, commercial and industrial sectors. For the moment, electricity demand in Cameroon is provided by hydroelectric power stations and oil or gas thermal power plants. The problems caused by the use of fossil fuels are well known: air pollution, greenhouse effect and aerosol production. Faced with this, it is possible that in certain specific cases other sources of so-called renewable energies such as solar energy and biomass are more profitable or more practical to implement. The renewable energy potential in Cameroon is as follows: AEEP-Cameroon (2013) [6].

- Hydroelectric potential: Cameroon's hydroelectric potential is very impressive with an estimated power of about $115 \mathrm{GWH} /$ year. However, the hydroelectric capacity used by the country represents only $4 \%$ of technically exploitable reserves.

- Solar potential: All regions of Cameroon benefit from a significant average annual sunshine: $4.5 \mathrm{kWh} / \mathrm{m}^{2} /$ day in the South and $5.74 \mathrm{kWh} / \mathrm{m}^{2} /$ day in the North.

- Biomass potential: Cameroon's potential to generate electricity from biomass waste is estimated at $1072 \mathrm{GWh}$, of which $700 \mathrm{GWh}$ could be exported to the grid.

- Potential of the wind: the important deposits are located at the extreme North (kaelé velocity of $2 \mathrm{~m} / \mathrm{s}$ ); in Mount Bamboutos (42 MW expandable); and in the coastal zone.

\subsubsection{Solar Power Plants}

Solar power plants use the energy contained in solar radiation and convert it into low voltage direct current. Solar systems, especially solar concentrating systems, are increasingly being used to help meeting energy needs. The technology of solar concentrators has just reached a very remarkable level, using reflectors to focus the sun's rays on a small area. Figure $7(a)$ and Figure 7 (b) show us pictures of cylindro-parabolic concentrator panels installed for house feeding in Figure $7(\mathrm{a})$. Figure $7(\mathrm{~b})$ shows a cylindro-parabolic concentrator field in a power plant. 


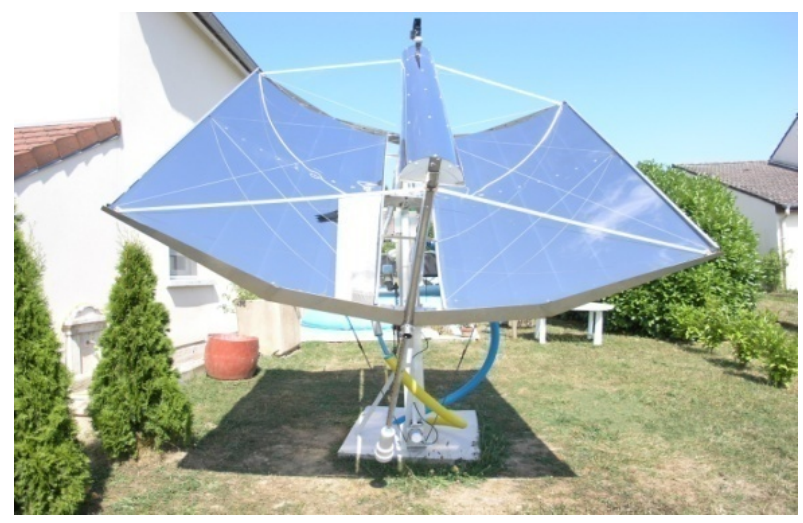

(a)

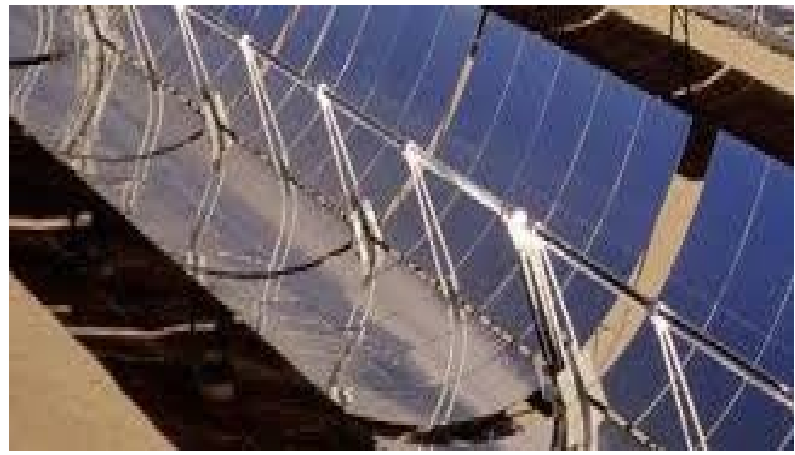

(b)

Figure 7. Solar panels with cylindro-parabolic concentrators.

\subsubsection{Biomass Plants}

Biomass is defined as all organic matter of animal or vegetable origin (industries, biodegradable household waste, wood, vegetable waste, algae, etc.) that can become a source of energy either by combustion or following one or more stages of transformation. There are many techniques for producing heat and electricity from biomass. Biomass can be upgraded to heat and/or electricity thermochemical or biochemical. Thermochemical treatments can be classified into four broad categories:

- Combustion allows a direct transformation of biomass into heat energy that can be used as such or converted into electricity.

- Cooking involves burning biomass with coal in traditional power plant boilers.

- Pyrolysis traditionally uses temperatures of $300^{\circ} \mathrm{C}$ to $600^{\circ} \mathrm{C}$ and produces charcoal.

- Gasification heats solid biomass at high temperatures in an oxygen-free environment to produce a combustible gas (or syngas).

- Cogeneration recovers the thermal energy normally lost during the production of electrical energy, and provides heat and electricity with a significantly higher overall efficiency than that resulting from separate dies.

The valorization electricity of the biomass can also be done by biochemical way. Anaerobic digestion of biomass produces a combustible gas called biogas.

Biomass is a renewable energy, clean, storable, low emitting greenhouse gas 
and whose recovery technologies are mature and proven (combustion boiler, digester). Biomass promotes rural job creation and decentralized energy production. Faced with the scarcity of fossil fuels, their rising prices, the geopolitical stakes linked to these energies and the awareness of the climate issues, biomass is one of the answers for sustainable energy production. In addition, the biomass boiler is a renewable energy that is storable and non-intermittent, compared to wind and solar energy. Figure 8 shows a bio-digester for storing organic waste decomposition occurs after the bigaz that can be used either for cooking or for the production of electricity.

\subsection{Potential of Electricity Saving in the Cameroonian Population}

\subsubsection{Potential Savings in the Tertiary Sector}

In the tertiary building sector, electricity conservation measures concern air conditioning and lighting. The potential savings of existing buildings are divided between short-term actions affecting the organization, awareness and strengthening of the maintenance program; and medium-term actions aimed at improving the performance of lighting and air conditioning. This objective is particularly sensitive for the public sector, whose lowering of the cost of electricity bills is an essential requirement. The reduction of electricity consumption is, therefore, an essential issue that is primarily based on the appointment and training of an energy manager in charge of managing awareness actions and the implementation of low-cost measures.

\subsubsection{Potential Savings in the Residential Sector}

The residential sector is characterized by a profound change in the level of household equipment as a result of development policies and the improvement of residents' income. Data on the decomposition of electricity use by households confirm the trend towards an ever greater share of electrical equipment. The savings potential is both presents in the improvement of household equipment today (lighting, televisions, refrigerators) but also in the goods that will be acquired in the coming years (housing, air conditioners, household equipment). In particular, housing construction has great potential for savings. Rather than "let

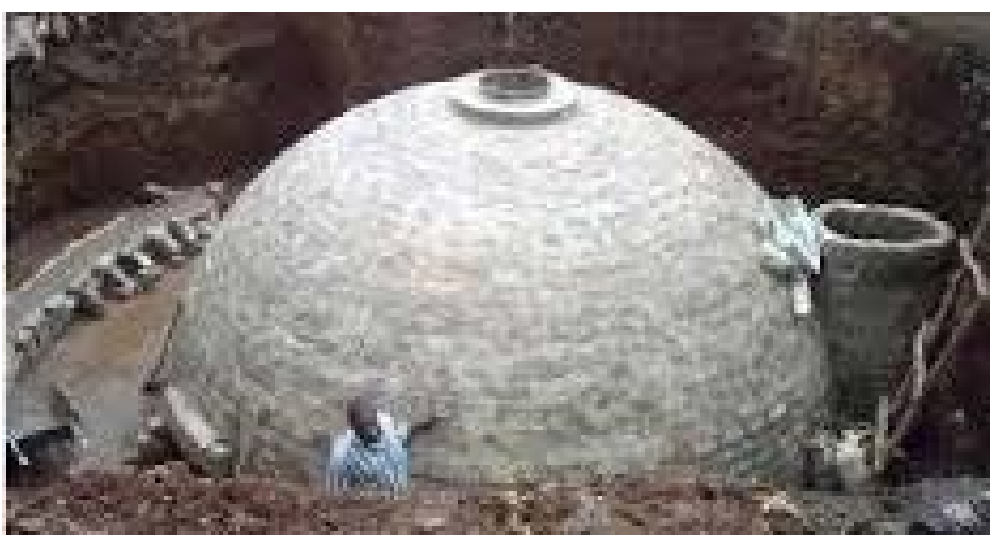

Figure 8. Example of a bio-digester. 
it go", energy efficiency measures must accompany the development of air conditioning housing: these measures must relate to the rules of construction (insulation, solar protection) and the performance of air conditioners (energy performance standards). In the residential sector even more than in other sectors targeted by the study, the significant savings potential estimated at $30 \%$ is based on the regulatory and normative approach. All domestic appliances used by households must be subject to the definition of minimum energy performance, either in a pure Cameroon context, or by reference to what is done in other countries, developed or developing.

\subsection{Empirical Studies}

The question of obtaining reliable prospective methods for electricity consumption has been widely discussed by past research. In addition, studies have also been done on electrification from green energies.

Nadejda Victor and Christopher Nichols (2014) [7] propose a regression method for forecasting annual electricity consumption in non-OECD countries. They find that the introduction of the brightness variable in addition to the socio-economic variables allows an improvement in the quality of electricity demand forecasting.

Speaking of electricity modeling in African countries, Helene Ahlborg et al. (2015) [8] analyzed the electrification of African households and gave the importance of a democracy and a quality institution for better electrification. They make a case study of 44 African countries from 1996 to 2009. Based on this analysis, it appears that democracy and a quality institution have a positive impact on the GDP of household electricity consumption. Oluremi Kayode et al. (2011) [9] used an econometric model (VAR and VECM) to estimate urban residential electricity demand in Nigeria. They suggest that this hybrid approach involving econometric and dynamic system techniques can lead to better forecasting of electricity demand in developing countries. Patrice Ongono (2010) [10] analyzes the impact of electricity consumption on global and sectoral (primary, secondary and tertiary) economic performance (GDP) in Cameroon by analyzing the causality between electricity consumption and GDP. Estimating a VAR model shows that a $1 \%$ increase in electricity consumption results in a $0.6 \%$ increase in value-added in services.

Numerous studies have evaluated the techno-economic feasibility of green energy supply projects. Neves D. et al. (2014) [11] presented a review of hybrid renewable energy systems for micro-communities in remote islands and villages. They found that data reporting is particularly weak for many of these projects and recommends a structured framework to facilitate analysis and evaluation. Zbigniew Chmiel et al. (2015) [12] analyzed the off-grid electrification system on Eigg Island in Scotland to optimize it. For this, he uses Homer software to model hybrid systems linking renewable energies and fossil fuels in order to reduce the use of fossil $\mathrm{CO}_{2}$-producing energies that cause climate change. They later be- 
lieve that this should be a lesson for developing countries. Subhes and C. Bhattacharyya (2015) [13] studied the electrification of an isolated village using mini-grids in Bangladesh. For this study, they use Homer software to perform a technical-economic analysis of the electrification of the village. They find that the best configurations for this site are the hybrid PV-diesel and wind-diesel systems. Subhes et al. (2016) [14] analyzed off-grid electrification from green energy mini-grids for developing countries. At the end of this study, they give ten recommendations for the promotion of mini-grids. Givler $T$ and Lilienthal $P$ (2005) [15] conducted a study on the electrification of Sri Lanka from hybrid systems. The study found that the PV-diesel hybrid was better than the others. H. Pettifo et al. (2015) [16] present one of the first empirical examinations of the success of the "green market" to influence owner renovation decisions. Using a repeated measure model in which households were interviewed before and after the launch of the "green market" in January 2013, they assessed the success of the energy efficiency awareness policy. Mohammed Ebrahim et al. (2016) [17] did a study to discuss the concept of the green economy in relation to renewable energies. They demonstrate the interdependence of the green economy and the quality of the environment as well as the compatibility of the green economy approach with the notion of sustainable development. In addition, this study illustrates the importance of $\mathrm{CO}_{2}$ emissions produced by biomass energy from fossil fuel combustion. I. K. Maji and C. Sulaiman (2019) [18] evaluate the impact of renewable energies on the economic growth of West African countries using dynamic ordinary least squares using a sample of 15 African countries West covering the period 1995-2014. The results show that renewable energy consumption is slowing economic growth in these countries. This is due to the use of woody biomass which is impure and highly polluting when burned. In addition, the use of solar, wind and hydro, which has no side effect on human health and the environment, is less widespread in West Africa. They conclude that the use of renewable energy can slow down economic growth by reducing productivity when unclean and inefficient sources are used. H. R. Bohlmann et al. (2019) [19] examine the long-term regional economic effects in South Africa of transforming the electricity mix into lower coal production. The overall results from all scenarios suggest that the effect of the transition to an energy mix with a smaller share of coal production is sensitive to other economic and political conditions, particularly the global coal market response, and hence to South Africa's coal exports. B.T. Olanrewaju et al. (2019) [20] study the determinants of renewable energy consumption in Africa (Nigeria (West), Egypt (North), Ethiopia (East), DR Congo (Central) and South Africa (South)), in order to understand the current pattern and its potential determinants using annual data from 1990 to 2015. The empirical analysis consisted of estimating fixed effects and random effects models, the Hausman test 2 was used to select the appropriate panel model and was significant at $\mathrm{p} \leq 0.05$. B. Ozcan and I. Ozturk (2019) [21] analyze the link between renewable energy consumption and economic 
growth in 17 emerging countries during the period 1990-2016. The bootstrap panel causality test, taking into account the dependency between countries and the heterogeneity of slope parameters, developed by Kónya (2006) was used. The results show that the neutrality assumption holds for all the markets studied, with the exception of Poland, which confirmed the growth hypothesis. The lack of causality from renewable energy demand to economic growth suggests that energy-saving (mitigation) policies have no detrimental effect on the growth rates of these 16 emerging economies. For Poland; however, energy-saving policies can have adverse effects on the country's level of economic performance. $R$. Antonietti and F. Fontini (2019) [22] analyze the relationship between energy intensity and energy price in a panel of 120 countries over a 34-year period, from 1980 to 2013. They use information on energy intensity and the real price of oil, and they merge them with macroeconomic data on countries. They identify a statistically significant, but small, negative effect of the real price of oil on energy intensity, which corresponds to a positive effect of energy price on energy efficiency. They argue that a global policy to raise oil prices would lead to a limited increase in average energy efficiency through more efficient use of energy, but this increase will be dynamic across regions. M. Aydin (2019a) [23] examine the relationship between renewable and non-renewable electricity consumption and economic growth using data for the period 1980-2015 for 26 OECD countries using two different approaches to panel causality in order to make a comparison. The results show that two-way causality is observed between non-renewable electricity consumption and economic growth. They conclude that policymakers should promote renewable electricity consumption to ensure energy security, reduce energy dependency and encourage economic growth. Aydin (2019b) [24] examines the relationship between economic growth and biomass energy use in the production function of Brazil, Russia, India, China and from South Africa, a BRICS country from 1992 to 2013. They use the Westerlund and Edgerton LM cointegrate panel integration test and the bootstrap panel causality test. They conclude that the BRICS countries should increase the use of biomass energy consumption for a sustainable environment, promoting economic growth and reducing energy dependence. $S$. Adams et al. (2018) [25] analyze the effect of renewable and non-renewable energy consumption and the type of regime on the economic growth of 30 sub-Saharan African (SSA) countries during the period from 1980 to 2012. They use cointegration and error correction tests based on heterogeneous panels and find a long-term relationship between the variables. The results show that while renewable and non-renewable energies have a significant positive effect on economic growth, non-renewable energies have a stronger growth effect than renewable energies. They conclude that democratic states have higher growth rates than autocratic states. M. Owusu (2018) [26] examines the causal interdependence between energy consumption, economic growth, and $\mathrm{CO}_{2}$ emissions in Ghana from 1960 to 2015 using Toda-Yamamoto and Granger causality tests. The cointegration approach Johansen and Johan- 
sen-Juselius and the autoregressive distributed shift limit test approach are used to test the cointegration relationship. The results show that the variables are cointegrated. The causality tests reveal that there is a Granger causality relationship between energy consumption and $\mathrm{CO}_{2}$ emissions. They conclude that there is a need to improve energy efficiency through technological advances and to invest in renewable energy to reduce excessive reliance on fossil fuels. A. Boukhelkhal and I. Bengana (2018) [27] examine the relationship between $\mathrm{CO}_{2}$ emissions, economic growth and electricity consumption in the face of trade openness and annual average temperature in four countries North African countries selected for the period 1971-2014. They use the autoregressive distributed delayed cointegration (ARDL) approach called the Bounds approach. The long-term analysis shows that economic growth and electricity consumption are the main cause of environmental degradation, while the increase in temperature over the year leads to an increase in electricity consumption. These results imply that environmental and economic remedies must be adopted to achieve green growth and sustainable development. SA Kourtzidis et al. (2018) [28] examine the relationship between energy use and US economic growth at both national and sectoral levels (Industry, Residential, Electric Power, and Transportation) using an asymmetric-threshold cointegration approach and monthly data from January 1991 to May 2016. Granger causality tests support a neutrality assumption for all sectors, except for the case of total consumption at the country level where unidirectional causality ranges from energy consumption to economic growth. $A$. Sinha et al. (2018) [29] analyze the causal link between economic growth, carbon emissions, fossil fuel and renewable energy consumption in 11 countries during the period 1990-2016. Empirical evidence confirms that a robust renewable energy policy can be designed by complementing the different results of the causality test, rather than focusing on a particular causality test. C. Tansel and M. Topcu (2018) [30] examine the long and short-term relationships between total renewable and non-renewable energy consumption and economic growth in the G7 countries over the period 1980-2014 using nonlinear autoregressive lateral shift (NARDL) and asymmetric causality approaches. The results indicate that the production function is important in determining cointegration between variables. The results strongly confirm an asymmetrical relationship between energy consumption and long-term economic growth.

GIS can be used to identify sites where potential renewable energy plants could be located. Studies have already been done to identify the appropriate areas for the development of renewable energy projects. This is D. Mentis et al. (2015) [31] who evaluated the wind power potential in Africa using GIS. They focused their study on onshore wind energy on the African continent and endeavored to provide estimates of theoretical, geographical and technical potential based on advanced wind energy technology. Wind potential maps at $80 \mathrm{~m}$, the height of the hub of a modern wind turbine, were derived through the statistical distribution of wind speed data and the implementation of wind curves. $A$. 
Yushchenko et al. (2018) [32] made a GIS-based assessment of the photovoltaic (PV) and concentrated solar energy (CSP) production potential in West Africa. They studied both the possibilities offered by large-scale grid-connected solar systems (photovoltaic and concentrated solar technologies) and off-grid (photovoltaic) solar systems. Locations were assessed for their ability to deploy solar systems based on topographical, legal and social constraints, as well as factors that could facilitate or hinder the development of solar generation. The results can be used to identify potential areas of interest for the deployment of solar generation, and as a support for integration between grid extension and off-grid electrification policies. T. R. Ayodele et al. (2018) [33] identified the most suitable sites for the development of wind farms in Nigeria. The data presented by the authors was obtained with an appropriate assessment of the wind resource taking into account environmental, social and economic factors. They believe that the information contained in the data could be useful for decision makers, public authorities, engineers, etc. to choose an optimal site. This will ensure optimum investment and return on investment for wind farm developers.

However, very few studies have been done in Africa and even less in Cameroon. An identification of the spatio_temporel potential and sites favorable for the implementation of renewable energies (solar-wind) will be a big step for the promotion of renewable energy in Cameroon. It will also convince and encourage public services to invest heavily in this sustainable energy source, which is the energy of the future.

\section{Methodology}

\subsection{Data}

NB: The consumption of Low Voltage customers in Cameroon is taken as the electricity consumption of the Cameroonian population because it is in this bracket that rural and urban households are found. The data used in this study come from the ENEO database and the INS (National Institute of Statistics). They are spread over the period 1975-2011. These data are: Gross Domestic Product (GDP) in real terms expressed in billions of CFA Francs (GDPG); tertiary GDP (GDPT); GDP per capita (GDPH); the electricity consumption of the Cameroonian population (CE); the population (PO); the number of households $(\mathrm{H})$; the number of subscribers $(\mathrm{S})$. In addition, they have undergone a logarithmic transformation. The ratings adopted are: $\mathrm{L}$ GDPH $=$ logarithm of real GDP; LGDPH = logarithm of GDP per capita; LGDPT = logarithm of tertiary GDP; LCE = logarithm of electricity consumption; LS = logarithm of the number of subscribers; $\mathrm{LH}=$ logarithm of the number of households; $\mathrm{LPO}=$ logarithm of population.

\subsubsection{Evolution of Socio-Economic Indicators and Electricity Consumption}

Figure 9(a) suggests a consistency between CE growth and different GDPs. The coefficients of determination between this consumption and the different GDPs 


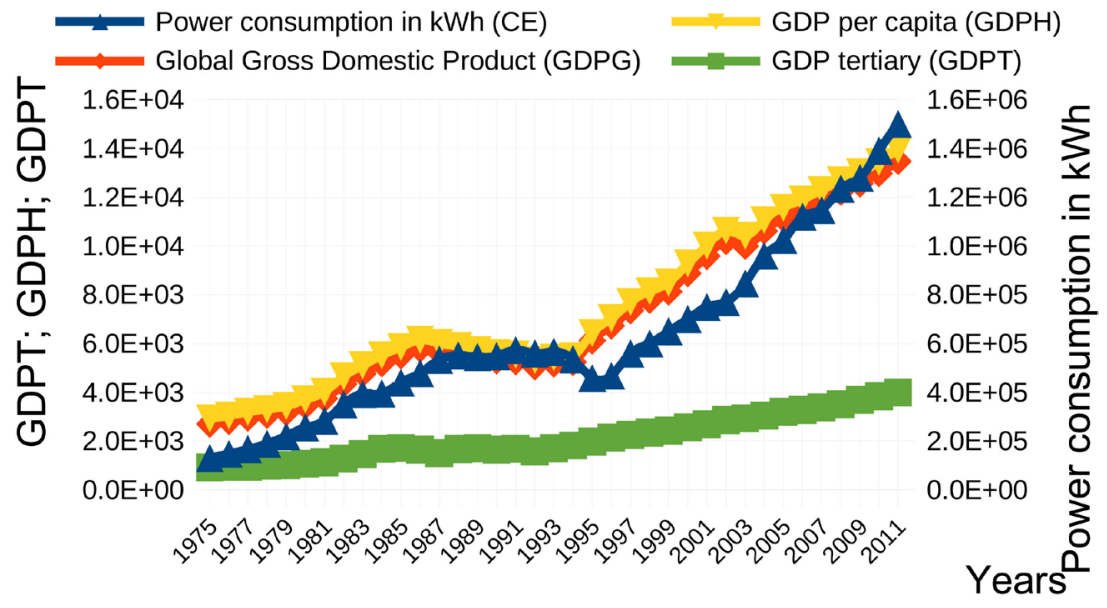

(a)

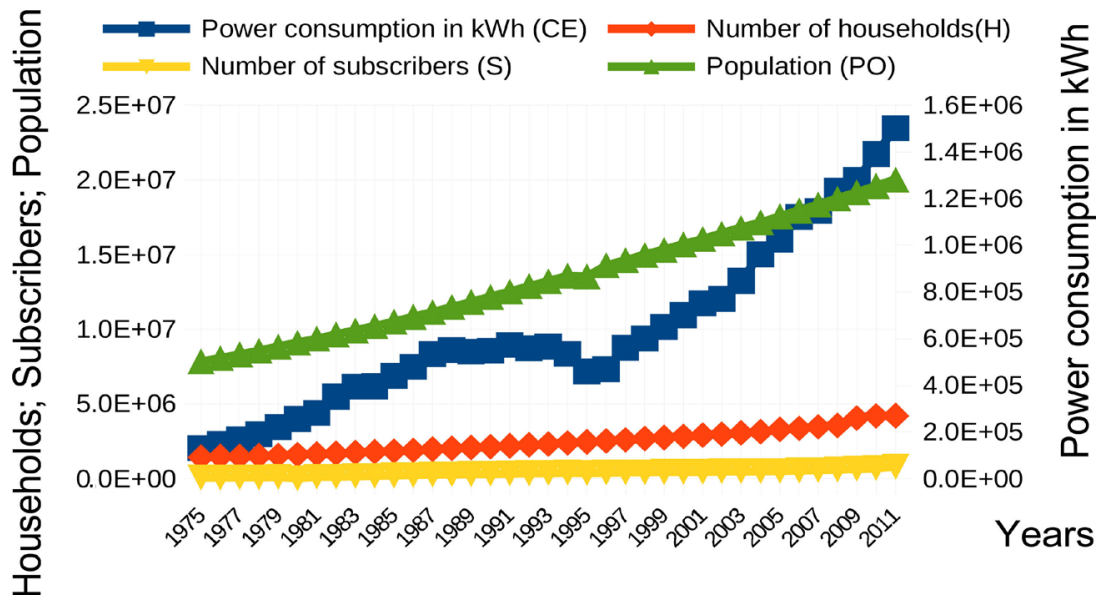

(b)

Figure 9. Evolution of CE curves and different macroeconomic indicators (GDP/per capita, Overall GDP and tertiary GDP) and demographic indicators (subscribers, households, population) (sources: B.D. ENEO 2012; INS 2012) [34] [35].

namely the GDPH, the GDPG and the GDPT are 0.7874 respectively; 0.9293 and 0.9422. The different GDPs, therefore, have a positive influence on the CE. We also find that all these variables increase with time, they are temporal or chronological data.

An examination of Figure 9(b) suggests that all socio-demographic indicators will grow in all periods. Electricity consumption followed this growth except for the period 1987-1995, which was marked by the devaluation of the FCFA. This has led to a decrease in the purchasing power of households and consequently a drastic drop in their consumption. The coefficients of determination between the consumption and the different demographic indicators namely the population $(\mathrm{PO})$ the households $(\mathrm{H})$ and the subscribers $(\mathrm{S})$ are respectively 0.9023 ; 0.9456 and 0.9133 . We observe a trend towards growth in electricity consumption with socio-economic indicators with few fluctuations. This can be explained by the significant share of the residential sector in this electricity consumption, estimated at $70.9 \%$ on average. 


\subsubsection{Scenarii for the Evaluation of Energy Efficiency}

For this work, we have developed two scenarios of electricity consumption to define an energy efficiency policy in Cameroon. These scenarios are based on different levels of public policy ambition to encourage or demand more efficient use of electricity. These two scenarios, called for the first, ambitious scenario and for the second standard scenario, are based on two different visions:

- Standard EE Scenario: This scenario describes the savings that can be achieved through a simple, low-cost program to achieve the most easily accessible energy savings;

- Ambitious EE Scenario: This scenario shows the results that can be achieved through a coherent and proactive program of multiple public actions to stimulate or impose the implementation of all measures that are technically and economically possible, that is to say, those whose return time is considered reasonable, depending on the sectors concerned.

In this study, we will only study the standard EE scenario as it is easier to set up than the ambitious EE scenario.

\subsubsection{Data for the Spatio_Temporal Analysis of the Solar and Wind Potential in Cameroon}

In order to arrive at an accurate and reliable estimate of the wind and solar potential in Cameroon, appropriate data were collected, modified and analyzed. Several sources are used not only for wind speed and solar irradiance data, but also for the existing energy supply in Cameroon, as well as data on population density. The data sources used for the completion of the project are presented in Table 2. The wind speed and solar irradiance data are used to define the wind and solar potential respectively. This data comes from the Worldclim 2.0 database and runs from 1970 to 2000 . The different maps were made using the QGIS 2.18 GIS software. Worldclim provides daily solar irradiation and wind speed data at $10 \mathrm{~m}$ above the ground at a grid resolution of $1 \mathrm{~km}{ }^{\star} 1 \mathrm{~km}$, which served

Table 2. Description of the study data.

\begin{tabular}{|c|c|c|c|}
\hline Data & Types (format) & Georeferenced & Sources \\
\hline Administrative limits of Cameroon (regions, departments, districts) & Vectoriel (shapefile) & Yes & GADM, 2018 \\
\hline \multicolumn{4}{|l|}{$\begin{array}{l}\text { Map of monthly average solar radiation over } 12 \text { months from } 1970 \text { to } 2000 \text { in } \\
\text { Cameroon }\end{array}$} \\
\hline $\begin{array}{l}\text { Map of average monthly wind speed over } 12 \text { months } \\
\text { from } 1970 \text { to } 2000 \text { in Cameroon }\end{array}$ & Raster $\left(1 \mathrm{~km}^{2}\right)$ & Yes & Worldclim version 2 \\
\hline Map of the density of the population in Cameroon & Raster (1 ha) & Yes & Wordpop, 2018 \\
\hline Map of Cameroon Power Plants & Vector (shapefile) & Yes & World Bank, 2018 \\
\hline Hydrological map of Cameroon (streams, navigable waters, rivers, wetlands, reservoirs...) & Vector (shapefile) & Yes & \\
\hline Map of land use in Cameroon & Vector (shapefile) & Yes & OSM, 2018 \\
\hline Map of the road network (inter_state, primary, secondary roads...) in Cameroon & Vector (shapefile) & Yes & \\
\hline Map of Cameroon power grid & Vector (shapefile) & Yes & World Bank, 2018 \\
\hline
\end{tabular}


as a starting point for estimating resource potential. For each cell in the grid, for each cell in the network, a wind speed distribution curve was calculated using Worldclim data, extrapolated to the hub height of the proposed wind turbine $(100 \mathrm{~m})$.

\subsubsection{Data on Existing Thermal Power Plants in Cameroon}

From Table 3, we find that the power plants (grid-connected plants) are used exclusively in the RIS area and have a capacity of $121 \mathrm{MW}$; the RIN add-in plants are not used. This is due to the fact that the hydraulic production of the RIN can supply all the population connected to its network. Moreover, we notice a power of $2.64 \mathrm{MW}$ for the thermal power plants isolated from the RIS against 5.39 MW for the RIN and 11.5 MW for the RIE. These isolated power plants cover mainly peri-urban and rural areas. The design of renewable mini-grids will take into account the type of region and the renewable energy potential of the region.

\subsection{Methodology}

In this study, the Eviews 7.0 software [36] was used to determine the relationship between electricity consumption and various socio-economic parameters.

\subsubsection{Co-Integration and Causality}

This section aims to analyze the relationship between Cameroonian people's electricity consumption (LCE) and socio-economic indicators (LGDPG, LGDPT, LGDPH, LPO, LH, LS).

\section{1) Stationarity test}

This test aims at determining the order of integration of the variables. There are several types of stationarity tests. The Dickey Fuller Augmented (Dickey et al., 1981) [37] and Phillip-Perron tests were selected for this work on the Eviews 7.0 software.

\section{2) Co-integration test}

The cointegration theory makes it possible to study non-stationary series but

Table 3. Peak power, duration of use and energy emitted from thermal power plants in 2011 in Cameroon (ESDP, 2012) [38].

\begin{tabular}{|c|c|c|c|}
\hline Thermal power plants & $\begin{array}{l}\text { Peak power } \\
\text { in MW }\end{array}$ & $\begin{array}{c}\text { Duration of use of the } \\
\text { peak of electricity in } \\
\text { hours/year }\end{array}$ & $\begin{array}{c}\text { Output } \\
\text { energy MWh }\end{array}$ \\
\hline Thermal connected to the RIS network & 121 & 2582 & 298365 \\
\hline Thermal connected to the RIN network & 0 & 0 & 0 \\
\hline $\begin{array}{l}\text { Total Thermal connected to the network } \\
\text { (RIN + RIS) }\end{array}$ & 121 & 2582 & 298365 \\
\hline Total Thermal Isolated RIS & 274 & 3700 & 9999 \\
\hline Total Thermal Insulated RIE & 1150 & 4392 & 49494 \\
\hline Total Thermal Insulated RIN & 539 & 4688 & 2504200 \\
\hline Total Thermal Insulated (RIN + RIS + RIE) & 1963 & 4377 & 84535 \\
\hline
\end{tabular}


of which a linear combination is stationary. It makes it possible to specify stable long-term relationships while simultaneously analyzing the short-term dynamics of the variables considered. Our series have different orders of integration, we will choose Johansen's technique (Engle, R.F et al., 1981) [39] [40] [41].

\section{3) Granger causality test}

Knowledge of the causal relationship between socio-economic variables provides elements of reflection for a better understanding of socio-economic phenomena. The Granger concept is retained in the case of this study. According to Granger, a stationary variable $X_{t}$ causes another stationary variable $Y_{t}$, if the knowledge of past values of $\mathrm{X}_{\mathrm{t}}$ makes the predictability of $\mathrm{Y}_{\mathrm{t}}$ (Engle, R.F et al., 1981) [39] [40] [41].

\subsubsection{Assessment of Energy Efficiency Gain}

The action plan developed for each of the electricity consumption sectors as well as for the supply sector (generation, transmission and distribution of electricity) comprises different types of measures which are listed in Table 4 . We have colored in red in Table 4. The percentages of the measures to be taken for the evaluation of energy savings among the Cameroonian population in the short term (EE Standard scenario, 10\%).

Table 4. Electricity Savings and Energy Efficiency Measures Costs EUEI-PDF and ARSEL (2013) [42].

\begin{tabular}{|c|c|c|c|}
\hline \multirow{2}{*}{$\begin{array}{l}\text { Categories of measures } \\
\text { Energy Ef }\end{array}$} & \multicolumn{3}{|c|}{ Energy saving } \\
\hline & $\begin{array}{l}\text { As } \% \text { of annual electricity } \\
\text { consumption of the country* }\end{array}$ & $\begin{array}{c}\text { In } \\
\text { GWh/year }\end{array}$ & $\begin{array}{l}\text { In } \mathrm{k} \\
€ / \text { year }\end{array}$ \\
\hline Energy Efficiency Act & $\mathrm{N} / \mathrm{A}$ & - & - \\
\hline $\begin{array}{c}\text { Establishment standardization procedure } \\
\text { labeling }\end{array}$ & $2.0 \%$ & 10.7 & 675 \\
\hline $\begin{array}{c}\text { Establishment of certification procedure for } \\
\text { auditors and energy managers }\end{array}$ & $0.5 \%$ & 2.7 & 225 \\
\hline Education and Training Programs & $0.5 \%$ & 2.7 & 135 \\
\hline Document Center & $0.8 \%$ & 4.3 & 180 \\
\hline Support for industrial energy audits & $9 \%$ & 48.4 & 1575 \\
\hline Support for cogeneration & $12 \%$ & 64.5 & 3075 \\
\hline Audit of buildings & $1.5 \%$ & 8.0 & 1035 \\
\hline Managers of public buildings & $1.0 \%$ & 5.5 & 704 \\
\hline Building Codes ${ }^{* *}$ & $2.0 \%$ & 10.8 & 1375 \\
\hline Public campaigns & $1.9 \%$ & 10.2 & 1305 \\
\hline $\begin{array}{l}\text { Replacement program for incandescent } \\
\text { lamps }\end{array}$ & $1.5 \%$ & 8.0 & 1035 \\
\hline Reduction of losses & $3.2 \%$ & 17.2 & 2200 \\
\hline TOTAL & & 193 & 22515 \\
\hline
\end{tabular}




\subsubsection{Spatio-Temporal Analysis of the Solar and Wind Potential in Cameroon}

The data used for the temporal-time analysis are rasters of resolution $1 \mathrm{~km} * 1$ $\mathrm{km}$. This is for the evaluation of the annual solar and wind potential, respectively for the monthly average solar irradiation and the average monthly wind speed. These monthly data were grouped into seasons (high season and low season) using the monthly average curve Figure 10(a) and Figure 10(b) to analyze the variations between seasons. Values above average represent the high season while data below this curve represent the low season.

\section{Results and Comments}

\subsection{Result of Cointegration and Causality}

4.1.1. Unit Root Tests (Augmented Dickey-Fuller and Phillip Perron Tests)

The test results of Dickey-Fuller Augmented and Phillip Perron executed under
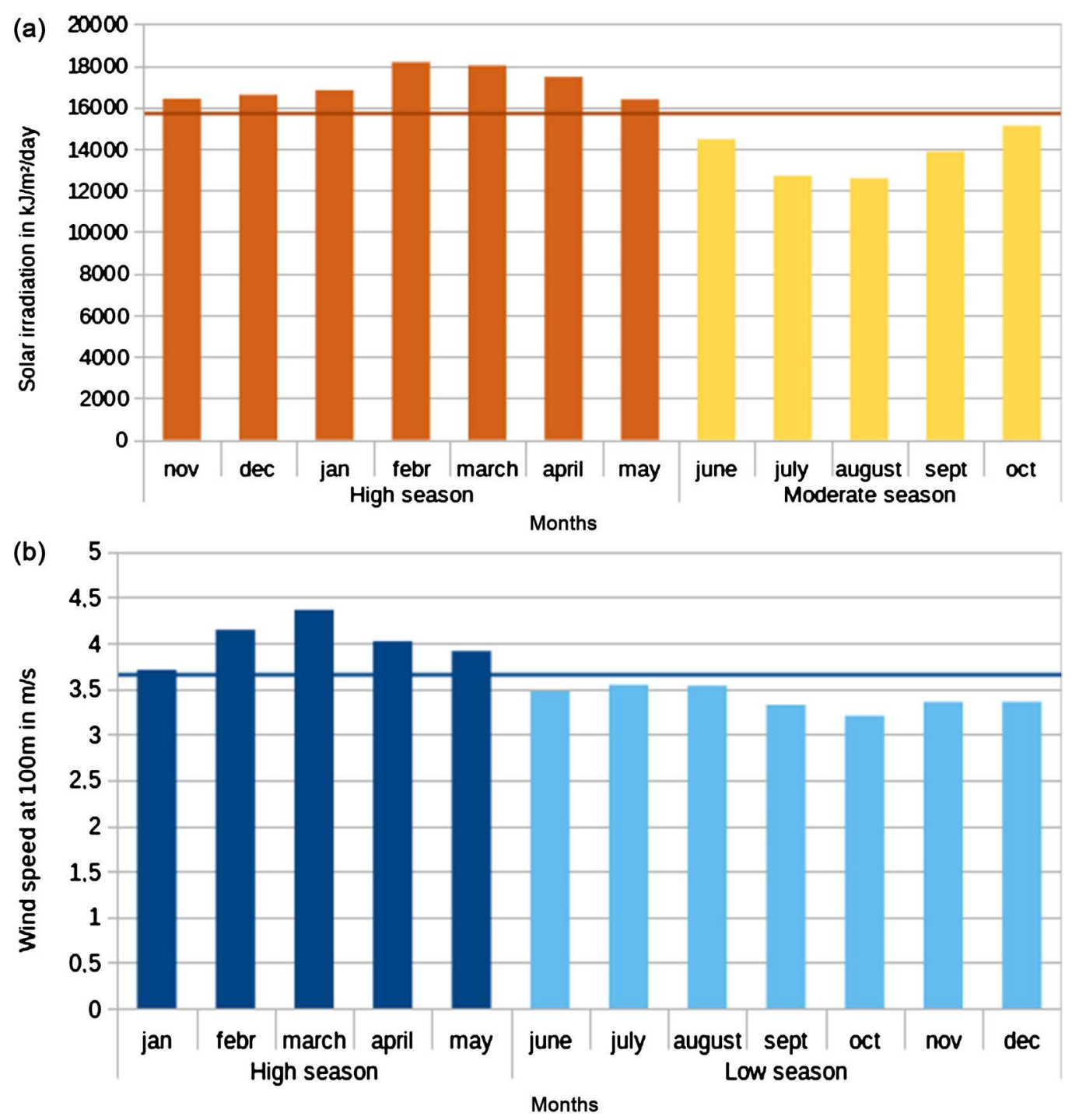

Figure 10. Average monthly solar irradiation (a) and average monthly wind speed (b) from 1970 to 2000 (Source: Worldclim 2.0, Author 2018) [43]. 
Eviews 7.2 [44] show that all series are integrated of order 1 with the exception of LPO and LA which are already stationary. The results of these tests are listed in Table 5.

\subsubsection{Cointegration}

In this work, we have used the Johansen cointegration test to determine the number of long-term equilibrium relationships between integrated variables, whatever the normalization used. The trace and maximum eigenvalue tests in Table 6 indicate that there is a cointegrating relationship between GDP per capita $(\mathrm{GDPH})$ and electricity consumption, two cointegration relationships between LCE and the population (LPO), and a cointegration relationship between LCE and the number of subscribers (LS). This is because the tests performed on the trace and the maximum eigenvalue $\left(\lambda_{\max }\right)$ have a value of the statistic strictly greater than the critical values at the $5 \%$ threshold. For the other variables, cointegration is rejected since we accept the null hypothesis of the existence of any cointegration relationship. The existence of cointegration relationships between electricity consumption and socio-economic indicators (LGDPH, LPO and LS) indicates that there is a long-term relationship between socio-economic growth and electricity consumption. Consumption growth could, therefore, follow socio-economic growth.

\subsubsection{Causality Test}

The absence of cointegration between two variables is not an indication of the

Table 5. Variables stationarity test results [45].

\begin{tabular}{|c|c|c|c|c|c|c|c|}
\hline \multirow{2}{*}{ Variables } & \multicolumn{2}{|c|}{ Differentiation of order 0} & \multicolumn{2}{|c|}{ Differentiation of order 1} & \multicolumn{2}{|c|}{ Differentiation of order 2} & \multirow{2}{*}{ Result } \\
\hline & p-value PP. test & p-value ADF. test & p-value PP. test & p-value ADF. test & p-value PP. test & p-value ADF. test & \\
\hline GDPH & 0.7657 & 0.7147 & 0.0079 & 0.006 & * & * & $\mathrm{d}=1$ \\
\hline GDPG & 0.9865 & 0.9933 & 0.0079 & 0.0079 & * & * & $\mathrm{d}=1$ \\
\hline GDPT & 0.9998 & 0.9999 & 0.0082 & 0.0084 & * & * & $\mathrm{d}=1$ \\
\hline PO & 1.0000 & 1.0000 & 0.0000 & 0.0000 & * & * & $\mathrm{d}=1$ \\
\hline $\mathrm{H}$ & 1.0000 & 0.8368 & 0.0008 & 1.0000 & 0.0001 & 0.9999 & $\mathrm{~d}=1$ \\
\hline$s$ & 0.9997 & 0.9998 & 0.0472 & 0.7145 & 0.0000 & 0.0000 & $\mathrm{~d}=1$ \\
\hline $\mathrm{CE}$ & 0.9999 & 1.0000 & 0.0529 & 0.0437 & 0.0000 & 0.0000 & $\mathrm{~d}=1$ \\
\hline LGDPH & 0.6305 & 0.5674 & 0.0070 & 0.0061 & * & * & $\mathrm{d}=1$ \\
\hline LGDPG & 0.7450 & 0.7245 & 0.0168 & 0.0168 & * & * & $\mathrm{d}=1$ \\
\hline LGDPT & 0.8879 & 0.8947 & 0.0036 & 0.0027 & * & * & $\mathrm{d}=1$ \\
\hline LPO & 0.0017 & 0.0000 & * & * & * & * & $\mathrm{d}=0$ \\
\hline LH & 1.0000 & 0.9979 & 0.0000 & 0.9688 & 0.0000 & 0.9999 & $d=1$ \\
\hline LS & 0.0002 & 0.0000 & * & * & * & * & $\mathrm{d}=0$ \\
\hline LCE & 0.3529 & 0.5823 & 0.0153 & 0.0154 & * & * & $\mathrm{d}=1$ \\
\hline
\end{tabular}

(Risk threshold 5\%). 
Table 6. Johansen test result.

\begin{tabular}{|c|c|c|c|c|c|c|c|}
\hline \multirow{2}{*}{ Variable } & \multicolumn{2}{|c|}{ Hypotheses } & \multicolumn{2}{|c|}{ Trace test } & \multicolumn{2}{|c|}{ Max eigenvalue test $\left(\lambda_{\max }\right)$} & \multirow{2}{*}{ Result } \\
\hline & HO & H1 & Trace test & Critical value at $5 \%$ & Max eigenvalue test & Critical value at $5 \%$ & \\
\hline \multirow[t]{2}{*}{ LCE and LGDPG } & $r=0$ & $r=1$ & 12.3576 & 15.4947 & & 14.2646 & 0 cointégration \\
\hline & $\mathrm{r} 1$ & $r=2$ & 1.2035 & 3.8414 & 1.2035 & 3.8414 & 0 cointégration \\
\hline \multirow[t]{2}{*}{ LCE and LGDPH } & $\mathrm{r}=0$ & $r=1$ & $\underline{15.7341}$ & 15.4947 & 13.4692 & 14.2646 & 1 cointégration \\
\hline & $\mathrm{r} 1$ & $r=2$ & 2.2648 & 3.8414 & 2.2648 & 3.8414 & 0 cointégration \\
\hline \multirow[t]{2}{*}{ LCE and LGDPT } & $\mathrm{r}=0$ & $\mathrm{r}=1$ & 10.6649 & 15.4947 & 9.9163 & 14.2646 & 0 cointégration \\
\hline & $\mathrm{r} 1$ & $r=2$ & 0.7485 & 3.8414 & 0.7485 & 3.8414 & 0 cointégration \\
\hline \multirow[t]{2}{*}{ LCE and LPO } & $r=0$ & $r=1$ & $\underline{29.3948}$ & 15.4947 & $\underline{23.3952}$ & 14.2646 & 2 cointégration \\
\hline & $\mathrm{r} 1$ & $\mathrm{r}=2$ & $\underline{5.9995}$ & 3.8414 & $\underline{5.9995}$ & 3.8414 & 2 cointégration \\
\hline \multirow[t]{2}{*}{ LCE and LH } & $r=0$ & $r=1$ & 12.9084 & 15.4947 & 10.4744 & 14.2646 & 0 cointégration \\
\hline & $\mathrm{r} 1$ & $\mathrm{r}=2$ & 2.4339 & 3.8414 & 2.4339 & 3.8414 & 0 cointégration \\
\hline \multirow[t]{2}{*}{ LCE and LS } & $r=0$ & $\mathrm{r}=1$ & $\underline{26.6844}$ & 15.4947 & $\underline{25.3330}$ & 14.2646 & 1 cointégration \\
\hline & $\mathrm{r} 1$ & $r=2$ & 1.3513 & 3.8414 & 1.3513 & 3.8414 & 0 cointégration \\
\hline
\end{tabular}

(_) significatif.

absence of Granger causality between these two variables. It will then test the latter on the different variables.

\section{1) Long term relationship}

We accept the null hypothesis (non-causality) as soon as the probability is greater than $5 \%$. An analysis of the results of the Granger causality tests presented in Table 7 reveals that there is a one-way causality relationship from macroeconomic indicators to electricity consumption. That is, from LGDPG to LCE, from LGDPH to LCE, and from LGDPT to LCE because the probability is less than $5 \%(0.0013,0.0044$ and 0.0044 respectively). The results of these tests also reveal that there is only one unidirectional relationship between LCE and demographic indicators, i.e. the relationship of LCE to LS (number of subscribers).

\section{2) Short term relationship}

We accept the null hypothesis (non-causality) as soon as the probability is greater than $5 \%$.

An analysis of the results of the Granger causality tests presented in Table 8 reveals that there is a one-way causality relationship from DLGDPG to DLCE and another one from DLGDPH to DLCE because the probability is less than 5\% (0.0358 and 0.0311 respectively). The results of these tests also reveal that there is no cause-and-effect relationship between DLCE and the other variables, since the probabilities associated with them are higher than the critical threshold of 5\% considered. We can then conclude that the indicators that have a better influence on electricity consumption are respectively the overall GDP for the macroeconomic indicators and the population for the socio-demographic indicators.

In sum, the tests indicate a unidirectional causality of GDPH towards electricity 
Table 7. Result of Granger causality tests for the long-term relationship

\begin{tabular}{ccc}
\hline Null hypotheses of causality in the sense of Granger & F-Statistics & Probability \\
\hline LGDPG does not cause LCE & 8.4123 & $\underline{0.0013}$ \\
LCE does not cause LGDPG & 0.1550 & 0.8570 \\
LGDPH does not cause LCE & 6.5390 & $\underline{0.0044}$ \\
LCE does not cause LGDPH & 0.5059 & 0.6080 \\
LGDPT does not cause LCE & 6.5845 & $\underline{0.0044}$ \\
LCE does not cause LPIBT & 0.5311 & 0.5935 \\
LPO does not cause LCE & 1.6311 & 0.2126 \\
LCE does not cause LPO & 0.2256 & 0.7994 \\
LH does not cause LCE & 2.6235 & 0.0891 \\
LCE does not cause LH & 0.6832 & 0.5127 \\
LS does not cause LCE & 0.0022 & 0.9977 \\
LCE does not cause LS & 6.4619 & 0.0046 \\
\hline
\end{tabular}

(_) significatif.

Table 8. Result of Granger causality tests for the short-term relationship.

\begin{tabular}{ccc}
\hline Null hypotheses of causality in the sense of Granger & F-Statistics & Probability \\
\hline DLGDPG does not cause DLCE & 3.7421 & $\underline{0.0358}$ \\
DLCE does not cause DLGDPG & 0.1466 & 0.8642 \\
DLGDPH does not cause DLCE & 3.9192 & $\underline{0.0311}$ \\
DLCE does not cause DLGDPH & 0.0711 & 0.9315 \\
DLGDPT does not cause DLCE & 1.19726 & 0.3165 \\
DLCE does not cause DLGDPT & 0.3761 & 0.6898 \\
LPO does not cause DLCE & 0.2639 & 0.7698 \\
DLCE does not cause LPO & 2.0008 & 0.1534 \\
DLH does not cause DLCE & 0.1698 & 0.8446 \\
DLCE does not cause DLH & 0.3339 & 0.7187 \\
DLS does not cause DLCE & 0.2555 & 0.7762 \\
DLCE does not cause DLS & 1.5572 & 0.2278
\end{tabular}

(_) significatif.

consumption and GDPG towards electricity consumption. This suggests that the GDPH and the GDPG explain the electricity consumption and the previous information on the GDPH and GDPG make it possible to better predict the EC level of the population in the short term. This result may be due to the fact that the creation of a product by a company requires the use of the factors of production to be paid, namely the labor factor for which it pays wages to households and the capital factor whose remuneration is gross operating surplus paid to owners. These different incomes are intended in part for consumption. An in- 
crease in production, therefore, leads to a greater income distribution and consequently an increase in consumption. Since electricity is a necessity, it will be consumed according to income. These analyzes, therefore, call for reflection on the implementation of an economic policy and energy efficiency in Cameroon.

\subsection{Potential in Renewable Energies in Cameroon}

\subsubsection{Solar and Wind Potential in Cameroon}

The grouping of months with an above-average value forms the peak season. These are November to May for average solar irradiation, and January to May for average wind speed (Figure 11 and Figure 12(a) and Figure 12(b)). Grouping months with below average value forms the low season. These are from June to October for average solar irradiation, and from June to December for average wind speed (Figure 11 and Figure 12(a) and Figure 12(b)). The average of these different months gives us a raster that characterizes this low season (Figure 13(a) and Figure 13(b)).

The seasonality is well-observed, because the months constituting the high and low seasons for the solar and the wind follow each other and there is no sudden break between two consecutive months. We note that the months of July and August are the months with the smallest solar irradiations. Meanwhile, the

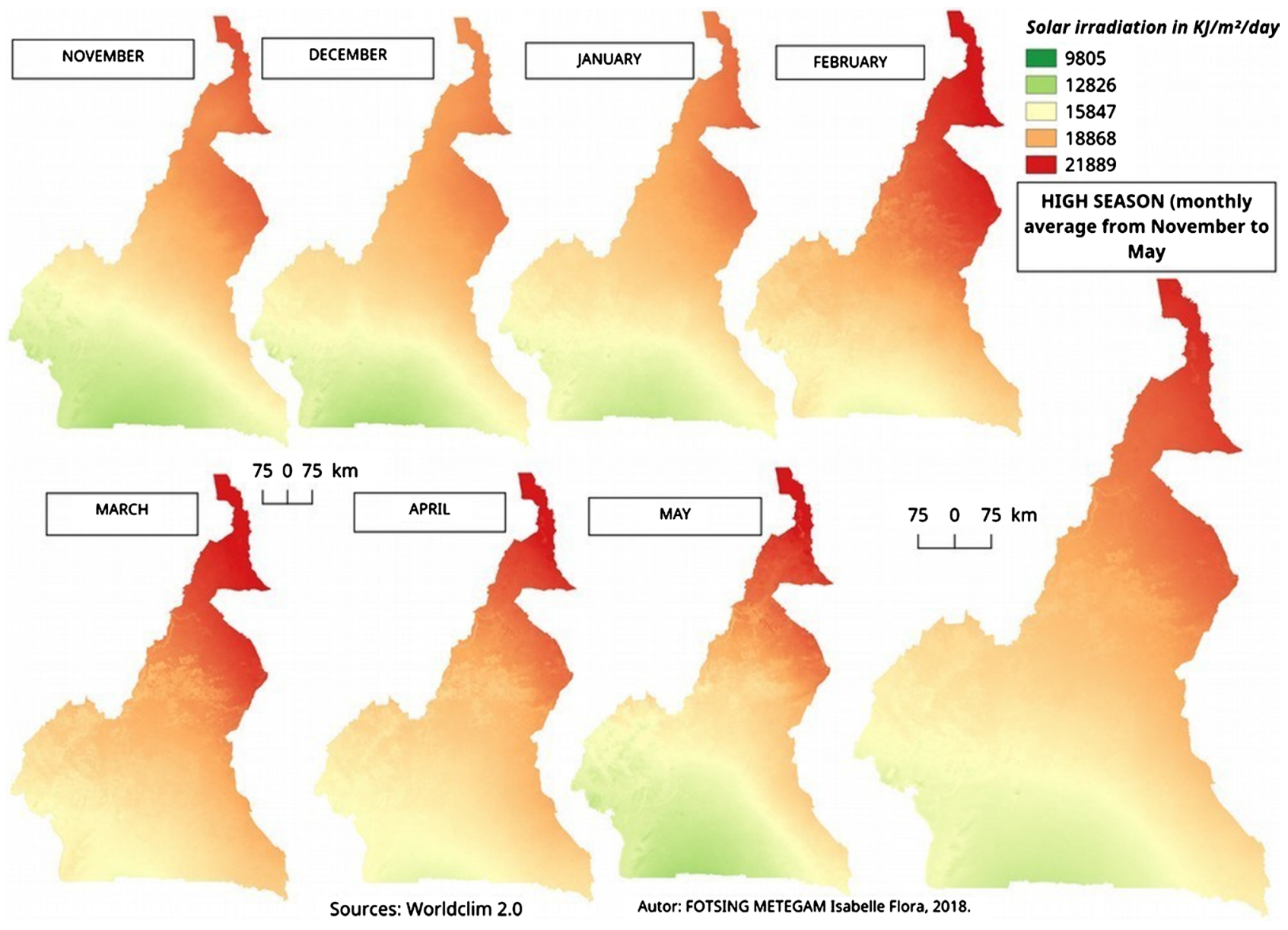

(a) 

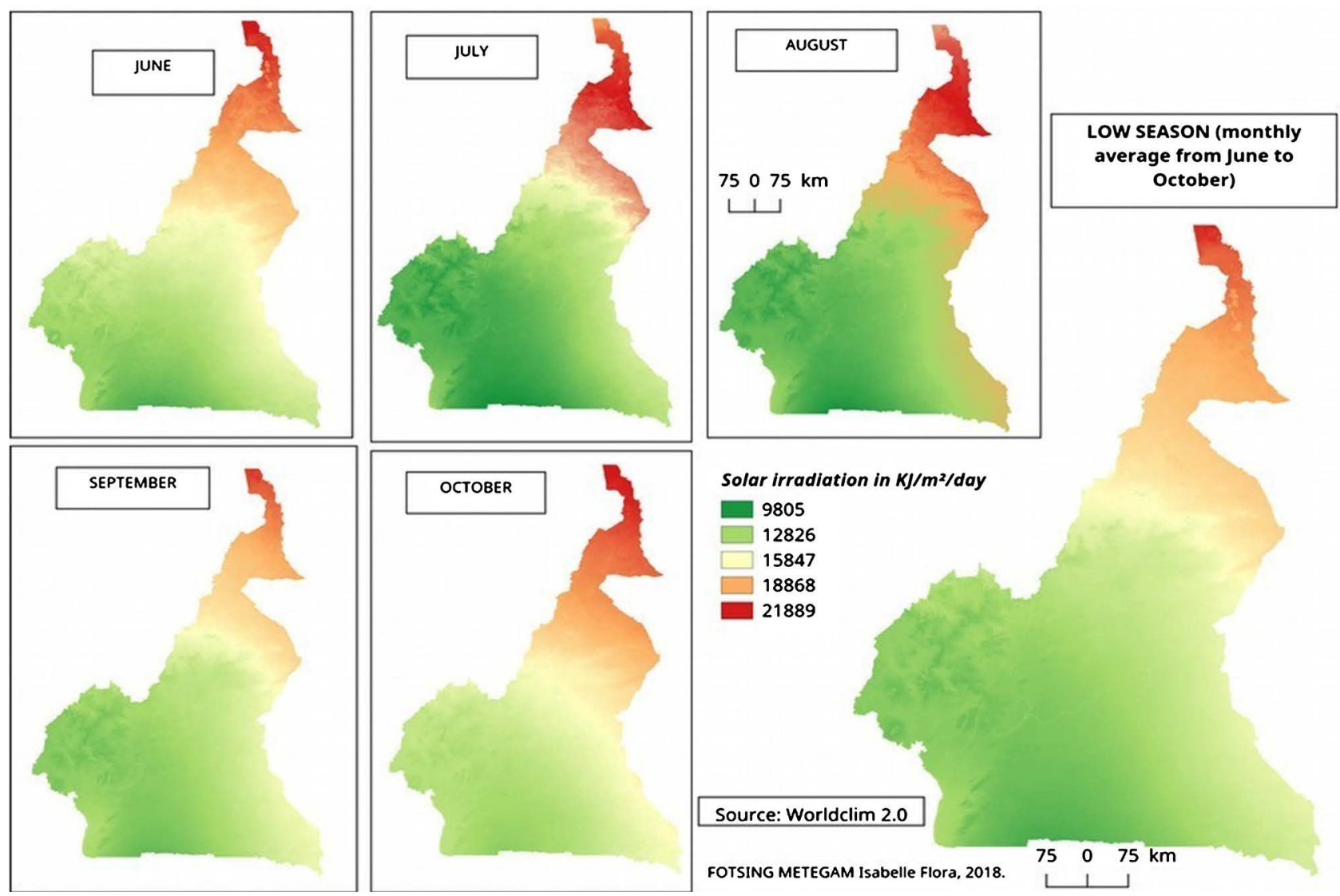

(b)

Figure 11. Spatio_seasonal variabilities of average solar irradiation (A high season and B low season) [46] [47].

month of October has the lowest wind speed. This could lead us to think that an association of a solar-solar hybrid system would make it possible to optimize the site of electricity production. Spatially speaking, we can also notice that areas with high solar and wind potential are grouped together in the same area (the Far North). This part of the country is also the one with the lowest electrification rate $(11.5 \%)$. This would already guide us to future sites if we want to combine need and potential.

The average of the high and low seasons allows us to have the solar and wind potential in the entire country. This is illustrated in Figure 10, which also shows the difference between the high and low seasons in order to spatially visualize the observed seasonal variability.

At the end of this analysis, we notice that the average solar irradiation minimum is $9805 \mathrm{~kJ} / \mathrm{m}^{2} /$ day and the maximum is $21,889 \mathrm{~kJ} / \mathrm{m}^{2} /$ day. This minimum value is already a good potential for solar. In addition, we notice that the average maximum wind speed at $50 \mathrm{~m}$ from the ground is $3 \mathrm{~m} / \mathrm{s}$. This value shows that the country has low wind potential. The area with average wind power potential is the Far North of the country. The Far North Zone (Adamawa, North and Extreme North) is the area with the highest solar potential. The graphs of Figure 2, Figures 11-13 were made with QGIS 2.18 software and Grass GIS 7 [46] [47]. 

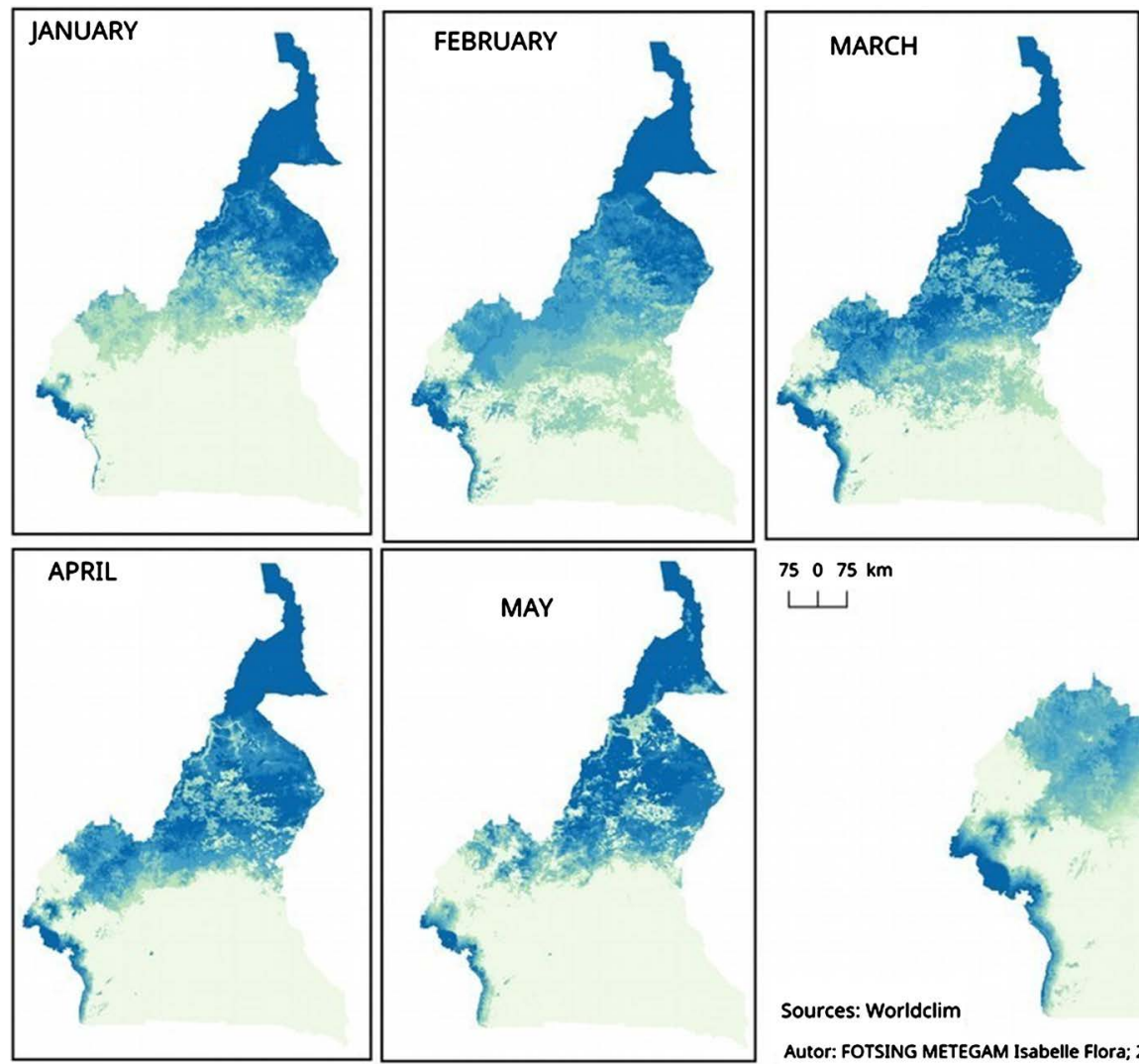

$75 \quad 0 \quad 75 \mathrm{~km}$

L.

Sources: Worldelim

Autor: FOTSING METEGAM Isabelle Flora; 2018

(a)
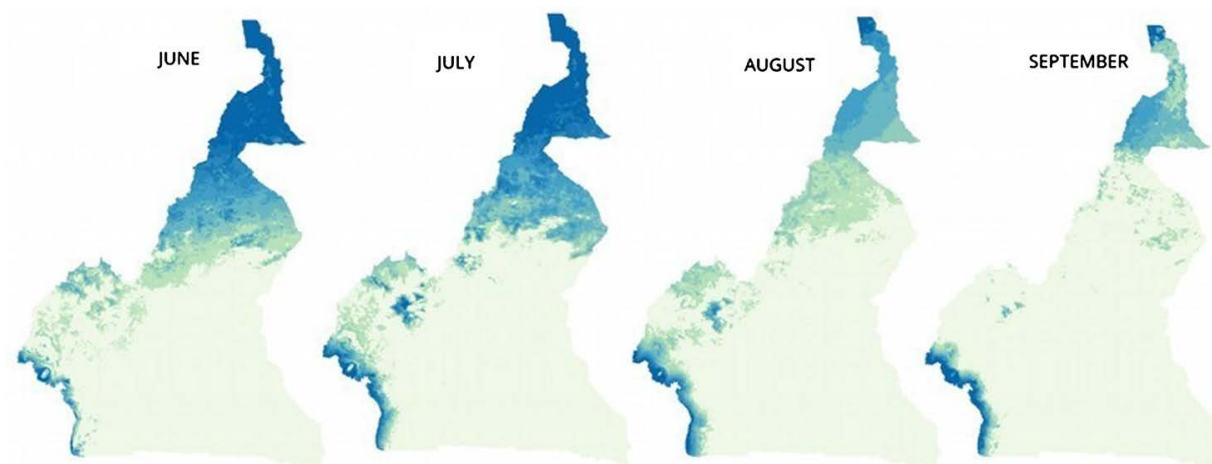

LOW SEASON (monthly average from June to

December)

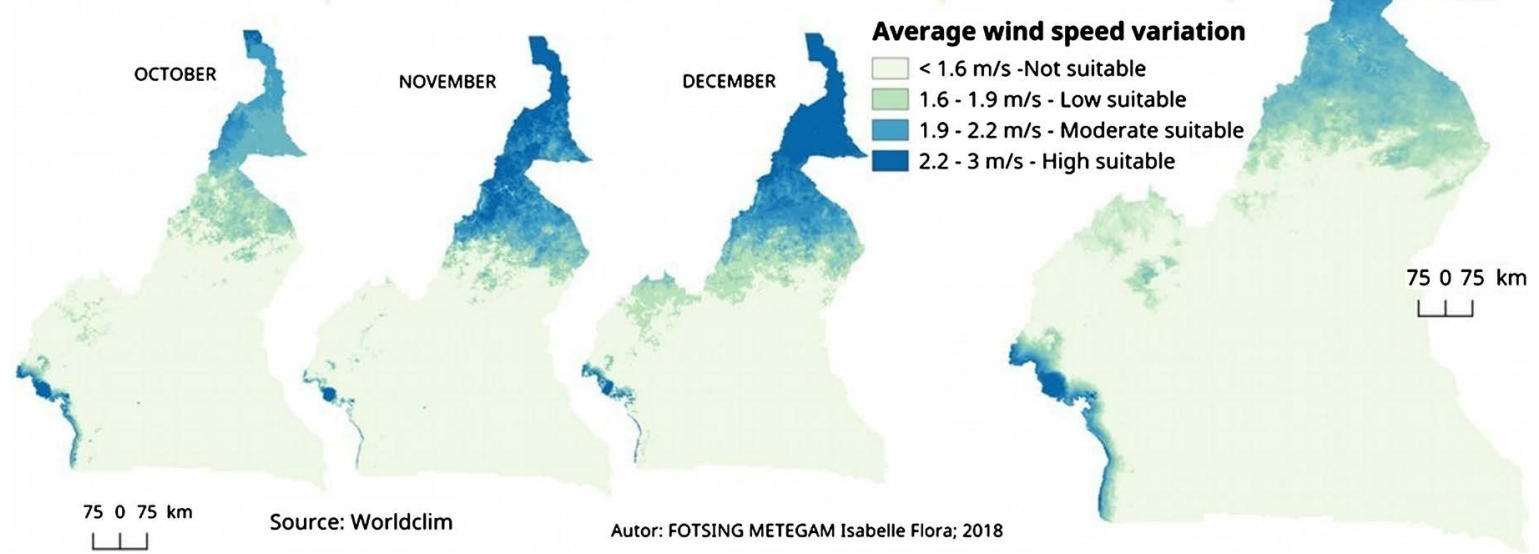

(b)

Figure 12. Spatio_seasonal variations of the average monthly wind speed (A season high and B season low) [46] [47]. 

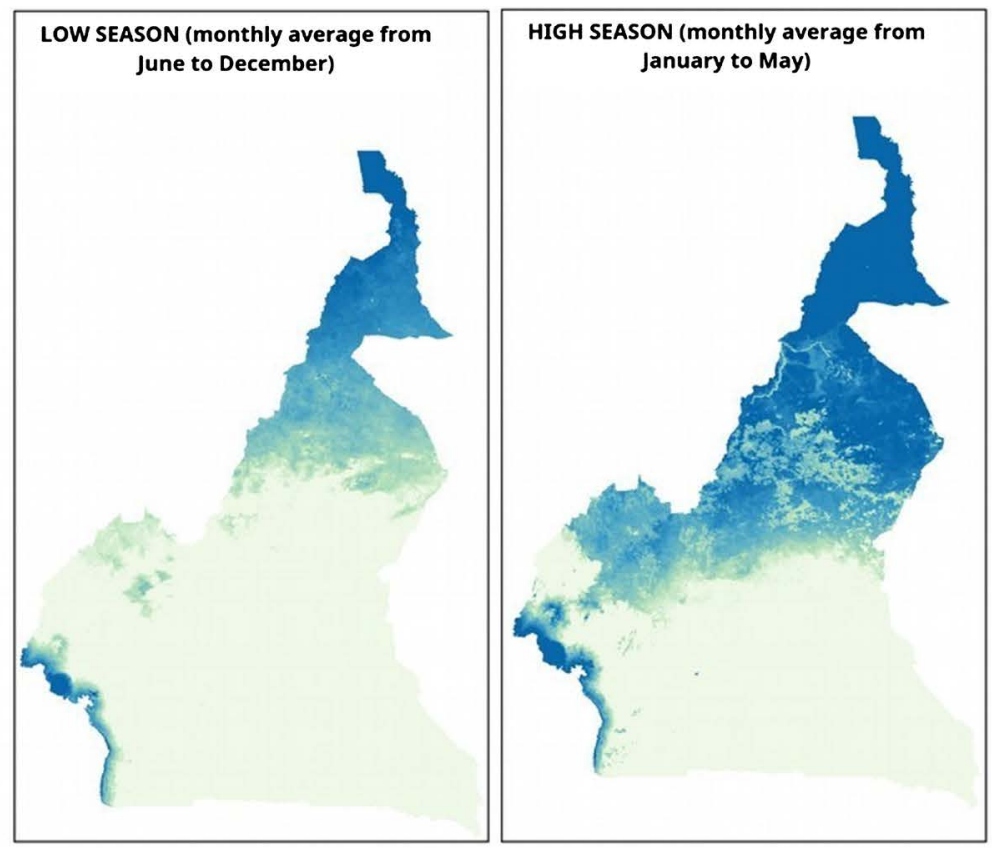

AVERAGE ANNUAL WIND SPEED (monthly average from January to December)

Average wind speed variation

$<1.6 \mathrm{~m} / \mathrm{s}$-Not suitable

$1.6 \cdot 1.9 \mathrm{~m} / \mathrm{s}$ - Low suitable

$1.9 \cdot 2.2 \mathrm{~m} / \mathrm{s} \cdot$ Moderate suitable

$2.2 \cdot 3 \mathrm{~m} / \mathrm{s}$ - High suitable

75075 km

Source: Worldclim

Autor: FOTSING METEGAM Isabelle Flora; 2018.

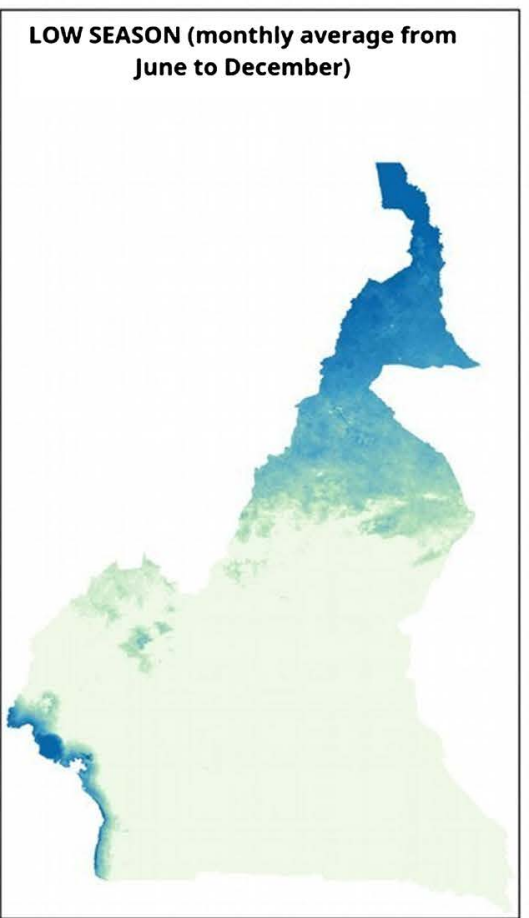

Average wind speed variation

$<1.6 \mathrm{~m} / \mathrm{s}-$ Not suitable

$1.6-1.9 \mathrm{~m} / \mathrm{s}$ - Low suitable

$1.9 \cdot 2.2 \mathrm{~m} / \mathrm{s}$ - Moderate suitable

2.2 - $3 \mathrm{~m} / \mathrm{s}$ - High suitable

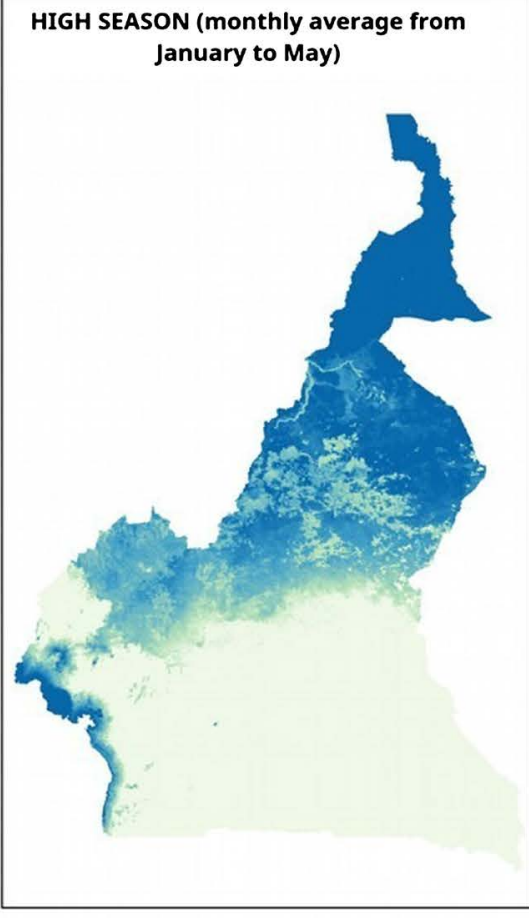

$75 \quad 0 \quad 75$ km

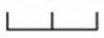

Source: Worldclim

Autor: FOTSING METEGAM Isabelle Flora; 2018.

\section{DIFFERENCE BETWEEN HIGH SEASON AND LOW SEASON}

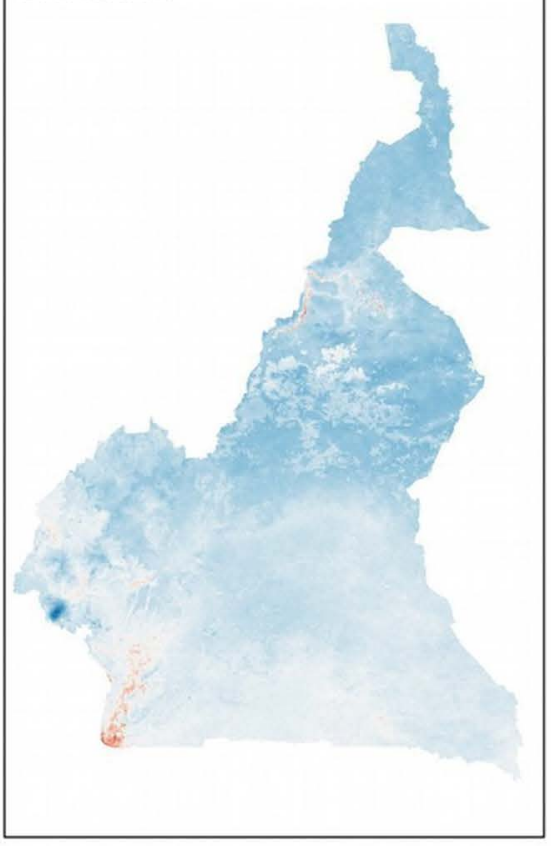

High season - Low season

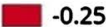

$-0.15$

$\square 0$

0.55

1.76

(a) 


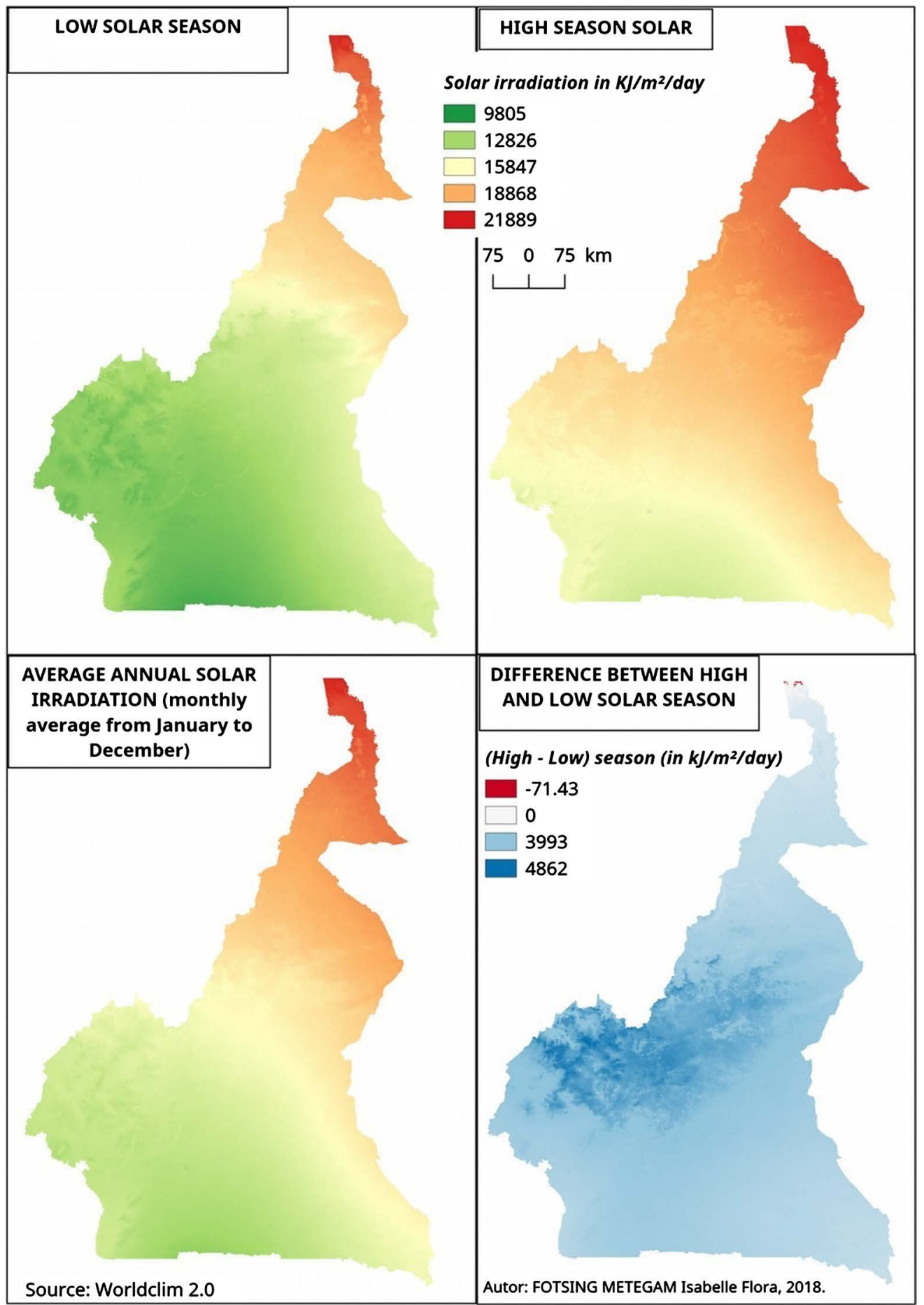

(b)

Figure 13. Spatio_temporal potential of solar and wind power in Cameroon [46] [47].

\subsubsection{Biomass Potential}

After examining Figure 14, we notice that the forest, the main source of biomass is mainly located in the South of the country. The eastern part of the country is mostly occupied by the forest. This region of the country is electrified by isolated thermal power stations. Biomass would be a solution for the electrification of 
this area. We also note that this area is a rural area and the population is very dispersed.

Isolated thermal power plants

Thermal power stations

Hydroelectric power stations

$\triangle$ Reservoir dams

Administrative limits

Wet area

Land use

Forests

Nature reserve

Parks

Residential areas

- Watercourses

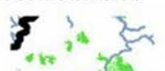

Y North-West
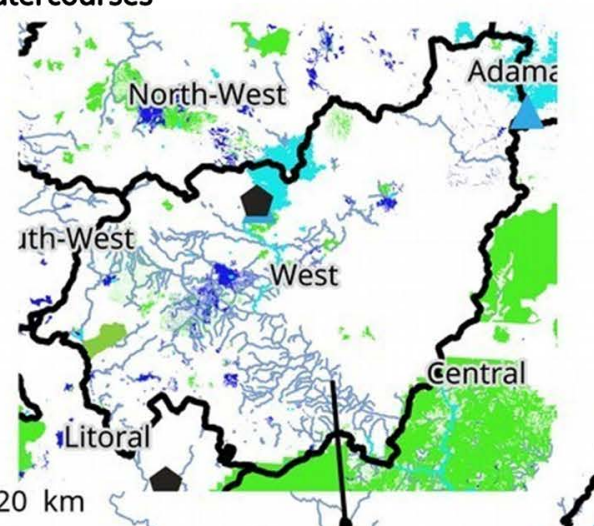

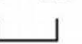

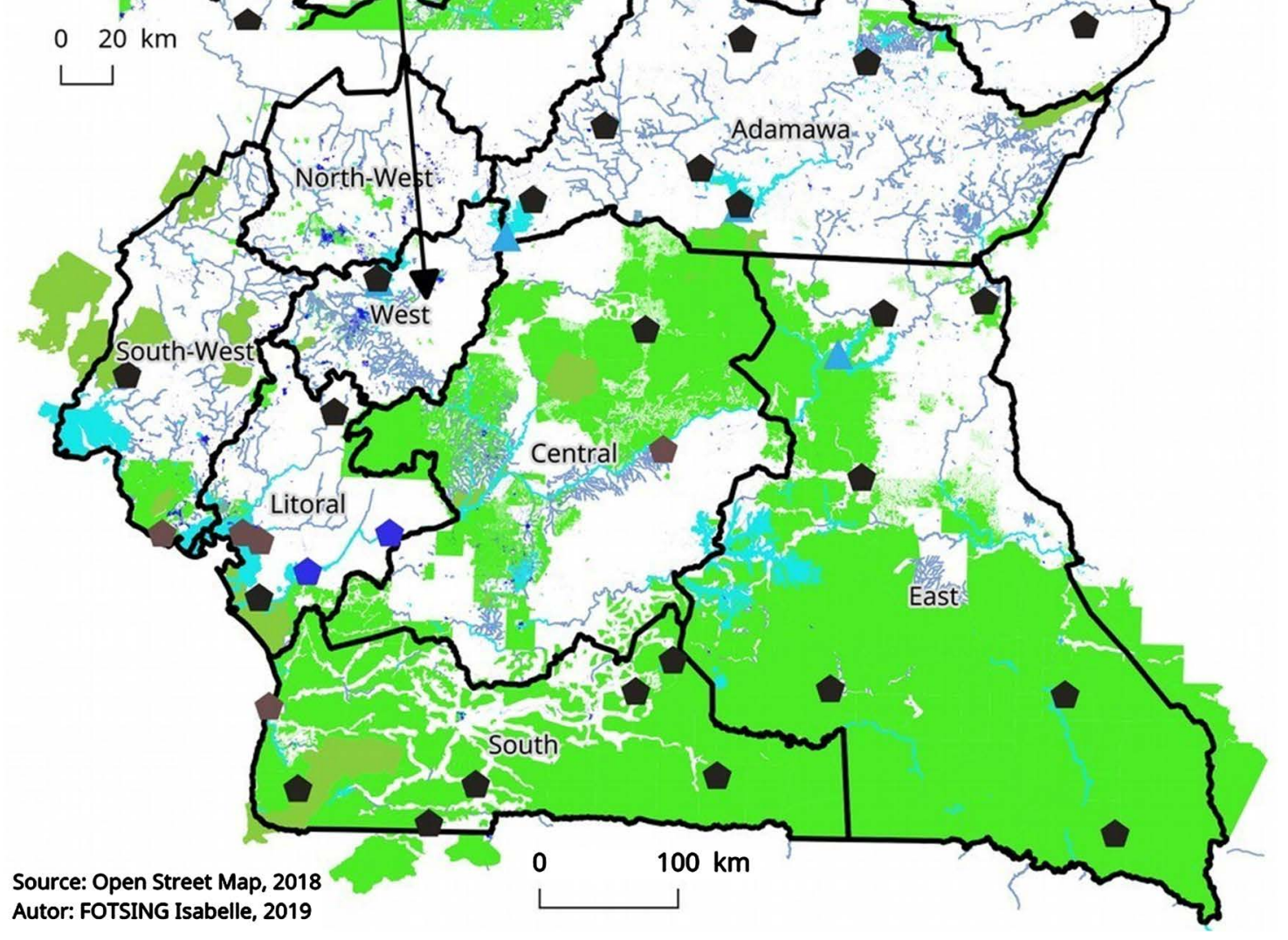

Figure 14. Landuse [46] [47]. 
NB: We remind all the same that the forest is only part of the biomass. We have not been able to quantify in Cameroon other biomass sources. Which justifies the absence of these sources in this study.

\subsection{Type of Mini-Networks Selected for Electrification in Cameroon}

Despite Cameroon's high hydropower potential, we have not retained it as a mini-grid for electrification in Cameroon, as the waterways are unevenly distributed and the installation of micro-hydroelectric power plants would be very expensive and maintenance of this one more tedious than the other types of plants with selected RES. However, hydropower plants will instead be offered for increased electricity generation on the interconnected South and North grid.

After determining the solar and wind potential in Cameroon, as well as the distribution of biomass, we can propose the type of renewable energy plant that can replace thermal power plants according to the RE potential of each zone. We already notice that the whole country enjoys a good solar potential over the whole of its territory.

The wind and biomass potential are not evenly distributed. We have average potential in the Far North of the country in wind and a high biomass potential in the far south of the country. Since biomass is a renewable and storable energy, we can exchange our thermal power stations (connected to the grid) by biomass plants. It must be remembered that these backup plants are mainly used at peak hours and spontaneously. Biomass plants respond very well to this type of use. The power stations being located in urban areas, the biomass used could be from the collection of household and industrial wastes. These wastes will be used to produce the biogas by methanisation and it will feed the plant.

Solar energy in Cameroon is characterized by its free availability, its availability throughout the national territory and the absence of risks of exhaustion that usually occur for fossil energy sources. Solar systems, especially solar concentrating systems, are increasingly being used to help meet energy needs. The technology of solar concentrators has reached a very remarkable level, using reflectors to focus the sun's rays on a small area. The technology of Cylindro-Parabolic Concentrators (CCP) is currently the most proven solar concentration techniques, it offers a good performance. Given all these advantages offered by the CCP, the design of mini-grids for the electrification of isolated areas will have to be made from solar PV systems. Cost-effective optimization and efficiency would be the use of hybrid solar/biomass systems in the far south and the Adamawa and North regions. Solar will be used during the day and biomass at night. This will reduce the investment cost of the plant, because batteries that cost about $40 \%$ in the investment cost of solar power plants will be reduced. The energy that should be stored by batteries to be restored at night will be directly produced using the biomass provided by rural populations. This will allow rural populations to contribute to the production of their electricity by collecting organic 
wastes or wood. An in-depth study of the area will allow us to know what kind of biomass will be optimal for the area. The regions of Adamawa and Northern Cameroon are areas where cattle are reared. The horse bursaries can be recovered for the production of biogas by methanation to supply the thermal power plants of these regions. In urban areas like Douala and Yaoundé, the high population density in these cities also leads to a high production of household wastes. These household wastes can be recovered and converted into fuel to supply thermal power plants in these cities.

In the Far north of the country, thanks to the good solar and wind potential in this region, using a hybrid wind-solar will be the most appropriate. In Cameroon, only $24 \%$ of the rural population is electrified, the establishment of mini-networks based on renewable energy will be an effective and sustainable solution for the electrification of isolated areas. Several EnR sizing software, like PVgis or HOMER, will allow us, after studying the area, to perform an optimal sizing of the different power plants both at the configuration level and at the cost and return-on-investment level.

\subsection{Gain of $\mathrm{CO}_{2}$ Emission}

The calculation of $\mathrm{CO}_{2}$ emission is done considering that all thermal power plants operate with fuel oil. The $\mathrm{CO}_{2}$ emission ratio of biomass plants is zero because the amount of $\mathrm{CO}_{2}$ emitted corresponds to the amount of $\mathrm{CO}_{2}$ absorbed by the plants during their growth. Moreover, we have seen that to reduce the investment cost, we will use solar energy on the day is 12 hours and the biomass at night, thus 12 hours. For the calculation of the energy emitted by the biomass solar hybrid power plant in isolated areas, half of the period of use will be used. Overall, Table 9 shows that a $\mathrm{CO}_{2}$ emission gain of $265,844 \mathrm{Kg}$ could be achieved by exchanging thermal power plants connected to the grid with biomass plants. A $\mathrm{CO}_{2}$ emission gain of $71,094 \mathrm{~kg}$ will also be observed if we exchange our isolated

Table 9. $\mathrm{CO}_{2}$ emissions from thermal power plants and $\mathrm{CO}_{2}$ emission savings with renewable energy plants (in $\mathrm{Kg} \mathrm{CO}_{2}$ eq/ $\mathrm{MWh}$ ).

\begin{tabular}{|c|c|c|c|c|c|}
\hline $\begin{array}{l}\text { Thermal power plants Duration } \\
\text { of use of the peak in hours/year }\end{array}$ & $\begin{array}{l}\text { Duration of use of the } \\
\text { peak in hours/year }\end{array}$ & $\begin{array}{l}\text { Output energy } \\
\text { MWh }\end{array}$ & $\begin{array}{l}\mathrm{CO}_{2} \text { emission of the } \\
\text { thermal power station } \\
\text { in } \mathrm{Kg} \mathrm{CO}_{2} \text { eq/MWh }\end{array}$ & $\begin{array}{l}\mathrm{CO}_{2} \text { emission of the } \\
\text { renewable energy plant } \\
\text { in } \mathrm{KgCO}_{2} \mathrm{eq} / \mathrm{MWh}\end{array}$ & $\begin{array}{c}\text { Gain of } \mathrm{CO}_{2} \\
\text { emission in } \mathrm{Kg} \\
\mathrm{CO}_{2} \text { eq/MWh }\end{array}$ \\
\hline Thermal connected to the RIS network & 2582 & 298365 & 265844 & 0 & 265844 \\
\hline Thermal connected to the RIN network & 0 & 0 & 0 & 0 & 0 \\
\hline $\begin{array}{l}\text { Total Thermal connected to the } \\
\text { network (RIN + RIS) }\end{array}$ & 2582 & 298365 & 265844 & 0 & 265844 \\
\hline Total Thermal Isolated RIS & 3700 & 9999 & 8910 & 500 & 8410 \\
\hline Total Thermal Insulated RIE & 4392 & 49494 & 44100 & 2475 & 41625 \\
\hline $\begin{array}{c}\text { Total Thermal Insulated (RIN + RIS + } \\
\text { RIE) }\end{array}$ & 4377 & 84535 & 75321 & 4227 & 71094 \\
\hline
\end{tabular}


thermal power plants for the benefit of biomass solar hybrid power plants. This makes a total $\mathrm{CO}_{2}$ emission gain of $336,938 \mathrm{Kg}$.

\section{Comments}

The continuation of current electricity consumption trends in Cameroon will lead to a situation of growing imbalance between supply and demand, which could only be partially offset by projected investment in new generation capacity, provided that, these can be however achieved in a timely manner and the corresponding substantial financial resources can be mobilized. The implementation of a vigorous energy efficiency policy in the electrical field would reduce the pressure on demand in the short term, which proves to be absolutely necessary. Energy efficiency can be defined as a catalog of good practices dedicated to save energy. It is the matter of consuming useful that is to arrive at the satisfaction of the energy need using the least energy with the least possible loss. Beyond the expected impact in terms of staggering the investments to be made to endow the country with additional power generation capabilities, the design and development of such an energy efficiency policy must, however, be seen as a foundation for any subsequent energy policy so as to limit the perpetual flight into new production tools which, even when based on the use of alternative energies to fossil fuels, do not require less heavy investments and significant funding. The durability of the energy efficiency policy to be put in place must, therefore, be a basic criterion when it is developed conceptually. This will be the level of the electrical system to reduce internal technical losses; at the household level, replacing incandescent lamps with inexpensive lamps is already a valuable step. But the biggest pole of waste is probably the public buildings, where state officials forget to turn off lamps and air conditioners when leaving the office. In addition, energy efficiency is now an important area of intervention for companies in charge of electricity. They use energy planning methods, including consideration of load curve management, promotion of efficient building components, and the use of standardization or labeling of household appliances that would allow to introduce technologies more adapted to the management constraints of the sector. In recent years, this policy has found new justifications in the fight against global warming through efforts to reduce greenhouse gas emissions in the power generation industry.

In addition, Cameroon has a huge potential in renewable energy resources, including hydraulics, biomass, solar energy. Several promising sites, of different sizes, and located in different parts of the country have been identified. The hydropower solution responds economically and efficiently to the needs of the sector. On the one hand, the development of hydropower can satisfy the growing demand of economic activities and expanding urban populations because large sites are located close to the population centers of the country and industrial zones (Douala). On the other hand, the installation of run-of-the-river micro 
hydroelectric power stations, which are sized in relation to the level of local demand, would gradually increase the rate of access to electricity for rural populations. The hydropower potential is enormous and could be the only one to exploit for the electrification of the whole country. However, the huge investment cost for the construction of a hydropower plant, the cost of interconnection infrastructures and the transport losses do not allow to have an optimal yield in the short and medium term. This is why it will be necessary to think of the mini-networks for the electrification of the isolated zones which in Cameroon are mainly the rural areas. Given that fossil fuel-based power plants emit GHGs that contribute to climate change, and that Cameroon enjoys a significant average amount of sunshine throughout the country and a large biomass. These mini-grids will have to be based on renewable energies for they are more respectful of the environment.

Many of the benefits derive from renewable energies and justify that they receive priority support beyond mere economic performance. These energies help to mitigate climate change, create jobs and generate sustainable local incomes, increase energy security and reduce dependence on imports.

\section{Conclusions}

This work aimed to determine the relationship between socio-economic indicators and the electricity consumption of the Cameroonian population. An assessment of the influence of energy efficiency and renewable energies on this consumption was also made. To carry out this work, we first listed the socio-economic indicators likely to influence this consumption, we then carried out various tests to identify those that really impact this consumption. Scenario tests involving energy efficiency on this consumption have also been made. We have also shown that to preserve our environment, fossil-fired power plants should be replaced by more environmentally friendly solar power plants and biomass plants. We have also shown that the establishment of renewable energy mini-grids for electrification in Cameroon was the optimal solution for reducing the imbalance between electricity supply and demand.

Solid planning for rural electrification in Cameroon is needed and must take into account the integration of mini-grids into the national grid. For this purpose, the areas dedicated to the extension of the network, the areas dedicated to the installation of mini-grids and those dedicated to the individual systems must be identified. Currently, the most modern methods use tools that determine the least costly planning based on geographic information (GIS tools).

Energy policies and strategies in Cameroon should focus on renewable energy resources, especially solar and biomass generation. In a favorable policy environment, the country needs to tap the untapped potential of solar and biomass generation, not only to meet the growing demand for electricity, but also to meet SDG-7 on clean and affordable energy. To achieve this goal, we suggest capitalizing on the recommendations we will cite below. 


\section{Recommendations}

\subsection{Recommendations for the State}

1) A stable political environment is crucial: political stability is essential. Investors should be assured that their investments will be secured.

2) A favorable environment for renewable energies and energy efficiency is required: contributing to preserving the environment, limiting climate change and its consequences, reducing fuel poverty and improving the living conditions of the population should be a key objective of the state. To do this, it will have to implement development engineering, specific technical expertise and offer specialized advice on the themes of energy efficiency, energy management, clean and renewable energy, energy and environmental management services. It will also be necessary to create a fair competitive environment for renewable energies: governments should work towards the gradual elimination of the harmful and inefficient policies of fossil fuel subsidies, policies that promote wastes and jeopardize sustainable development subsidizing and promoting renewable energy and energy efficiency by the state would be an asset.

3) Implementation of an energy efficiency policy: Develop minimum energy performance standards (MEPs) and labels for household lamps throughout the country. Develop complementary policies and mechanisms to ensure the successful implementation of PEMs (eg, lamp distribution programs, tax incentives, bill financing, etc.) and promote out network high-efficiency lighting products.

4) Technological transfer between northern and southern countries: a good knowledge of renewable energy technology is necessary so that their implementation is optimal and adapted to the context of Cameroon. Technology transfer in this context is, therefore, a process by which a technology, knowledge or know-how (hardware, software, organizational, etc.) developed by the countries of the North reaches the countries of the South. In addition, the communication of North-South know-how will have to be adapted to the context of Southern countries.

\subsection{Recommendations for the Electricity Management Company (ENE0)}

5) Implementation of smart-meters to control consumption: At the household level, Smart meter technologies are embodied in the form of advanced meters that communicate electricity consumption data on a daily basis at an automatic time to the distribution network manager. The data is analyzed by software and can be tracked by consumers on digital media such as smart phones, tablets, TV connected. It is easier for them to understand their consumption and to act on it by knowing, for example, equipment or the most energy-consuming habits or by deciding to consume at times when energy is cheaper, etc.

6) Establishment of a "Hollow Hours/Full Hours" billing: this would contribute to the reduction of the peak. From a technical point of view, electricity offers consist of a fixed part, the subscription, and a variable part, the supply, 
which is a function of electricity consumption. The differentiation of offers is mainly based on how to charge the kilowatt hour consumed. In Cameroon, we will be able to choose the offer called "Hollow Hours/Peak Hours" where the price of the kilowatt hour is modulated according to the periods of the day. This offer distinguishes off-peak hours with a relatively low kilowatt-hour price and peak hours with a higher kilowatt-hour price. Because the peak is observed between $6 \mathrm{pm}$ and $9 \mathrm{pm}$ and is due to the return of households, it would be interesting to educate households so that they can reduce their consumption during this peak period.

7) Energy conversion towards clean energy: replacement of thermal power plants using fossil fuels by renewable energy plants. Gradually, renewable energy technologies are reaching price levels that allow them to compete with fossil fuels. It is expected that investment technology developments will continue to pull down costs in renewable energy. Moreover, the sun and wind are renewable resources that are available at no cost. It is therefore likely that even without subsidies, renewable electricity will soon be competitive. This is because the costs of transitioning to a low-carbon economy do not differ significantly from the costs that will be incurred in any case to renew an aging energy system, cope with rising fuel prices fossils and respect policies in the fields of climate and energy. However, there will be a clear erasure of fuel costs in favor of innovative high value-added equipment, which will stimulate investment in innovative products and services, create jobs and simulate growth, and improve the trade balance.

8) Distribution of high-performance electricity: The losses of transmission and distribution network are one of the causes of this situation. Currently, the losses in power distribution in Cameroon both due to inefficient equipment, as well as to unpaid consumption-vary from $15 \%$ to almost $40 \%$ of the power generated.

\subsection{Recommendation for the Population}

9) Broad Public Awareness Campaign: As energy policy debates are often dominated by short-term price considerations, there is a need for a transparent public discussion of energy costs and tariffs. The general public should be provided with clear and comprehensive information so that it has a complete picture of the costs and benefits of the subsidies that can be granted to renewable energies, fossil fuels, including is their external impact on human health and the good state of the environment, or the benefits gained from saving on energy imports or energy security.

10) Swap energy-hungry appliances with appliances that consume less energy: Lighting is the most important use of electricity in Cameroonian households. The transition to energy-efficient lighting is one of the simplest and most cost-effective approaches to significantly reducing energy consumption and improving the quality of life of citizens. Conduct an awareness campaign on the benefits of low consumption lamps and the importance of recycling compact 
fluorescent lamps. Standards and labels for energy appliances and equipment are powerful tools for market transformation and the elimination of energy-intensive products.

\section{Acknowledgements}

This work would not have been possible without the valuable contribution of the United Nations University. We would like especially to thank Dr. Lat Souk TOUNKARA who met us in the Visiting Scientist Program UNU-IRNA (United Nations University) in Senegal in Food Technology Institute in Dakar and provided a work environment. We also thank the company ENEO in Cameroon for the provision of electricity data used in this work.

\section{Conflicts of Interest}

The authors declare no conflicts of interest regarding the publication of this paper.

\section{References}

[1] https://databank.banquemondiale.org/reports.aspx? source $=2 \&$ country $=\mathrm{CMR}$

[2] INS National Institute of Statistics (2010)

[3] https://www.worldpop.org/

[4] https://www.openstreetmap.org/\#map=6/7.402/12.343

[5] https://gadm.org

[6] AEEP-Cameroun (2013) Aperçu du marché électrique au Cameroun.

[7] Victor, N. and Nichols, C. (2014) Census from Heaven: An Estimate of Global Electricity Demand "If Everyone Lived Like in OECD". USAEE Working Paper No. 14-192. https://doi.org/10.2139/ssrn.2537064

[8] Ahlborg, H., Boräng, F., Sverker, C., et al. (2015) Provision of Electricity to African Households: The Importance of Democracy and Institutional Quality. Energy Policy, 87, 125-135. https://doi.org/10.1016/j.enpol.2015.09.002

[9] Kayode, O. and Nyamapfene, A. (2011) Urban Residential Energy Demand Modeling in Developing Countries: A Nigerian Case Study. The Pacific Journal of Science and Technology, 12, 152-159.

[10] Ongono, P. (2010) Energy Consumption and Economic Performance in Cameroon. MPRA Paper No. 23525.

[11] Neves, D., Silva, C.A. and Connors, S. (2014) Design and Implementation of Hybrid Renewable Energy Systems on Micro-Communities: A Review on Case Studies. Renewable \& Sustainable Energy Reviews, 31, 935-946. https://doi.org/10.1016/j.rser.2013.12.047

[12] Chmiel, Z. and Bhattacharyya, S.C. (2015) Analysis of Off-Grid Electricity System at Isle of Eigg (Scotland): Lessons for Developing Countries. Renewable Energy, 81, 578-588. https://doi.org/10.1016/j.renene.2015.03.061

[13] Bhattacharyya, S.C. (2015) Mini-Grid Based Electrification in Bangladesh: Technical Configuration and Business Analysis. Renewable Energy, 75, 745-761. https://doi.org/10.1016/j.renene.2014.10.034

[14] Bhattacharyya, S.C. and Palit, D. (2016) Mini-Grid Based Off-Grid Electrification to 
Enhance Electricity Access in Developing Countries: What Policies May Be Required? Energy Policy, 94, 166-178.

[15] Givler, T. and Lilienthal, P. (2005) Using HOMER ${ }^{\circledR}$ Software, NREL's Micro Power Optimization Model, to Explore the Role of Gen-Sets in Small Solar Power Systems Case Study: Sri Lanka. Technical Report NREL/TP-710-36774.

https://www.osti.gov/bridge https://doi.org/10.2172/15016073

[16] Pettifor, H., Wilson, C. and Chryssochoidis, G. (2015) The Appeal of the Green Deal: Empirical Evidence for the Influence of Energy Efficiency Policy on Renovating Homeowners. Energy Policy, 79, 161-176.

[17] Hussien, M.E., Siwar, C., Alam, R.Z., et al. (2016) Green Economy and Renewable Energy Focusing on the Biomass Energy Source. Journal of Sustainable Development, 9, 56. https://doi.org/10.5539/jsd.v9n3p56

[18] Maji, I.K. and Sulaiman, C. (2019) Renewable Energy Consumption and Economic Growth Nexus : A Fresh Evidence from West Africa. Energy Reports, 5, 384-392. https://doi.org/10.1016/j.egyr.2019.03.005

[19] Bohlmann, H.R., Horridge, J.M., Inglesi-lotz, R., Roos, E.L. and Stander, L. (2019) Regional Employment and Economic Growth Effects of South Africa's Transition to Low-Carbon Energy Supply Mix. Energy Policy, 128, 830-837. https://doi.org/10.1016/j.enpol.2019.01.065

[20] Olanrewaju, B.T., Olubusoye, O.E., Adenikinju, A. and Akintande, O.J. (2019) A Panel Data Analysis of Renewable Energy Consumption in Africa. Renewable Energy, 140, 668-679. https://doi.org/10.1016/j.renene.2019.02.061

[21] Ozcan, B. and Ozturk, I. (2019) Renewable Energy Consumption-Economic Growth Nexus in Emerging Countries: A Bootstrap Panel Causality Test. Renewable \& Sustainable Energy Reviews, 104, 30-37. https://doi.org/10.1016/j.rser.2019.01.020

[22] Antonietti, R. and Fontini, F. (2019) Does Energy Price Affect Energy Efficiency? Cross-Country Panel Evidence. Energy Policy, 129, 896-906. https://doi.org/10.1016/j.enpol.2019.02.069

[23] Aydin, M. (2019) Renewable and Non-Renewable Electricity Consumption Economic Growth Nexus: Evidence from OECD Countries. Renewable Energy, 136, 599-606. https://doi.org/10.1016/j.renene.2019.01.008

[24] Aydin, M. (2019) The Effect of Biomass Energy Consumption on Economic Growth in BRICS Countries: A Country-Specific Panel Data Analysis. Renewable Energy, 138, 620-627. https://doi.org/10.1016/j.renene.2019.02.001

[25] Adams, S., Kwame, E., Klobodu, M. and Apio, A. (2019) Renewable and Non-Renewable Energy, Regime Type and Economic Growth. Renewable Energy, 125, 755-767. https://doi.org/10.1016/j.renene.2018.02.135

[26] Owusu, M. (2018) Investigating the Multivariate Granger Causality between Energy Consumption, Economic Growth and $\mathrm{CO}_{2}$ Emissions in Ghana. Energy Policy, 112, 198-208. https://doi.org/10.1016/j.enpol.2017.10.017

[27] Boukhelkhal, A. and Bengana, I. (2018) Cointegration and Causality among Electricity Consumption, Economic, Climatic and Environmental Factors: Evidence from North-Africa Region. Energy, 163, 1193-1206. https://doi.org/10.1016/j.energy.2018.08.163

[28] Kourtzidis, S.A., Tzeremes, P. and Tzeremes, N.G. (2018) Re-Evaluating the Energy Consumption-Economic Growth Nexus for the United States: An Asymmetric Threshold Cointegration Analysis. Energy, 148, 537-545. https://doi.org/10.1016/j.energy.2018.01.172 
[29] Sinha, A., Shahbaz, M. and Sengupta, T. (2018) Renewable Energy Policies and Contradictions in Causality: A Case of Next 11 Countries. Journal of Cleaner Production, 197, 73-84. https://doi.org/10.1016/j.jclepro.2018.06.219

[30] Tansel, C. and Topcu, M. (2018) Total, Renewable and Non-Renewable Energy Consumption and Economic Growth: Revisiting the Issue with an Asymmetric Point of View. Energy, 152, 64-74. https://doi.org/10.1016/j.energy.2018.03.128

[31] Mentis, D., Hermann, S., Howells, M., Welsch, M. and Siyal, S.H. (2015) Assessing the Technical Wind Energy Potential in Africa a GIS-Based Approach. Renewable Energy, 83, 110-125. https://doi.org/10.1016/j.renene.2015.03.072

[32] Yushchenko, A., de Bono, A., Chatenoux, B., Patel, M.K. and Ray, N. (2018) GIS-Based Assessment of Photovoltaic (PV) and Concentrated Solar Power (CSP) Generation Potential in West Africa. Renewable and Sustainable Energy Reviews, 81, 2088-2103. https://doi.org/10.1016/j.rser.2017.06.021

[33] Ayodele, T.R., Ogunjuyigbe, A.S.O., Odigie, O. and Jimoh, A.A. (2018) On the Most Suitable Sites for Wind Farm Development in Nigeria. Data in Brief, 19, 29-41. https://doi.org/10.1016/j.dib.2018.04.144

[34] Base de données Eneo Cameroun (2012).

[35] INS (National Institute of Statistics) (2012).

[36] https://www.academia.edu/31479997/Introduction_au_logiciel_EViews

[37] Dickey, D.A. and Fuller, W.A. (1981) Likelihood Ratio Statistics for Autoregressive Time Series with a Unit Root. Econometrica, 49, 1057-1072. https://doi.org/10.2307/1912517

[38] ESDP (2012) Mise à jour du plan de développement du secteur de l'électricité à l'horizon 2030-Étude de la demande. STUDI International, Tunis.

[39] Engle, R.F. and Granger, C.W.J. (1987) Co-Integration and Error Correction: Representation Estimation and Testin. Econometrica, 55, 251-276. https://doi.org/10.2307/1913236

[40] Granger, C.W.J. (1969) Investigating Causal Relations by Econometric Models and Crossspectral Methods. Econometrica, 37, 424-438. https://doi.org/10.2307/1912791

[41] Granger, C.W.J. (2003) Some Aspects of Causal Relationships. Journal of Econometrics, 112, 69-71. https://doi.org/10.1016/S0304-4076(02)00148-3

[42] EUEI-PDF and ARSEL (2013) Development of a National Energy Efficiency Policy, Strategy and Action Plan in Cameroon. Inception Report.

[43] http://www.worldclim.org

[44] EViews. http://www.eviews.com

[45] Fotsing, F.I.M., Njomo, D. and Tchinda, R. (2014) Flora Isabelle Métégam Fotsing, Donatien Njomo, Réné Tchinda. Influence of Socio-Economic Indicators on Electricity Consumption of Low Voltage Customers in Cameroon. International Journal of Energy and Power Engineering, 3, 186-203. https://doi.org/10.11648/j.ijepe.20140304.13

[46] https://grass.osgeo.org/grass7

[47] https://docs.qgis.org/2.18/fr/docs 